OPEN ACCESS

Edited by: Jenia Mukherjee, Indian Institute of Technology Kharagpur, India

Reviewed by: Mahalaya Chatterjee, University of Calcutta, India Gopa Samanta

University of Burdwan, India

*Correspondence:

Subham Mukherjee subham.m@fu-berlin.de

Specialty section

This article was submitted to Water and Human Systems, a section of the journal Frontiers in Water

Received: 13 December 2021 Accepted: 20 January 2022 Published: 15 February 2022

Citation:

Mukherjee S, Sundberg T, Sikdar PK and Schütt B (2022) An Integrated Quantitative Assessment of Urban Water Security of a Megacity in the Global South. Front. Water 4:834239. doi: 10.3389/frwa.2022.834239

\section{An Integrated Quantitative Assessment of Urban Water Security of a Megacity in the Global South}

\author{
Subham Mukherjee ${ }^{1 *}$, Trude Sundberg ${ }^{2}$, Pradip Kumar Sikdar ${ }^{3}$ and Brigitta Schütt ${ }^{1}$ \\ ${ }^{1}$ Institute of Geographical Sciences, Physical Geography, Freie Universität Berlin, Berlin, Germany, ${ }^{2}$ Q-Step Centre, School \\ of Social Policy, Sociology and Social Research (SSPSSR), University of Kent, Canterbury, United Kingdom, ${ }^{3}$ Department of \\ Environment Management, Indian Institute of Social Welfare and Business Management, Kolkata, India
}

Water security, the access to adequate amounts of water of adequate quality, is and will remain a hugely important issue over the next decades as climate change and related hazards, food insecurity, and social instability will exacerbate insecurities. Despite attempts made by researchers and water professionals to study different dimensions of water security in urban areas, there is still an absence of comprehensive water security measurement tools. This study aims to untangle the interrelationship between biophysical and socio-economic dimensions that shape water security in a megacity in the Global South-Kolkata, India. It provides an interdisciplinary understanding of urban water security by extracting and integrating relevant empirical knowledge on urban water issues in the city from physical, environmental, and social sciences approaches. To do so we use intersectional perspectives to analyze urban water security at a micro (respondent) level and associated challenges across and between areas within the city. The study concludes with the recommendation that future studies should make use of comprehensive and inclusive approaches so we can ensure that we leave no one behind.

Keywords: water scarcity, water access, water quality, governance, intersectionality

\section{INTRODUCTION}

Water security is defined as "the availability of an acceptable quantity and quality of water for health, livelihoods, ecosystems, and production, coupled with an acceptable level of water-related risks to people, environments, and economies" (Grey and Sadoff, 2007, p. 548), which embodies a complex, multi-dimensional, and interdependent set of issues (Wheater, 2015). Water Security represents multiple challenges to twenty first century water management and crucial to achieve Sustainable Development (Cook and Bakker, 2012; UN, 2015). As a Sustainable Development Goal, water security has three primary dimensions: environmental, economic, and social (Giddings et al., 2002). To achieve "sustainability and security" within water security, each of these three dimensions should be addressed. While water scarcity has historically been more severe in rural areas, emerging research has shown a worsening availability and quality of water in urban areas and thus, urban areas are the focus of this study (Maiti and Agrawal, 2005; Mohan et al., 2011; Cook and Bakker, 2012; Mukherjee et al., 2020, 2021). From the rapidly changing urban perspective, the dimension of water security includes a focus ons the need for organizational and institutional flexibility and capabilities to address increasing uncertainty and change, a need for social capital and adaptive governance, and the need for engagement with stakeholders in knowledge exchange (Wheater, 2015). Thus, the interface between the scholars, practitioners and stakeholder communities has 
been increasingly important for the measurement and management of Urban Water Security (UWS) (Wheater and Gober, 2014). To address and better capture the multidimensional issues related to and driving water security, this study creates a quantitative index based on social, economic, cultural, and bio-physical dimensions of water security, specifically focusing on water availability, water accessibility, water quality, and risks associated with water.

UWS issues are particularly pertinent and show insufficient conditions in megacities in the developing world due to rapid and unplanned demographic and economic growth. India is one of the emerging economies where UWS issues are non-satisfying (Shaban and Sattar, 2011; Shaban et al., 2020; Chatterjee and Roy, 2021). In urban India, the rapid population growth combined with increasing levels of consumption and pollution has increased water insecurities (Shaban and Sattar, 2011; Mukherjee et al., 2018). UWS here relates to both the physicalenvironmental and societal barriers to access, availability, and quality of water for drinking, food production, hygiene, and sanitation (Obani and Gupta, 2016). Among the megacities in India, we chose Kolkata (under jurisdiction of Kolkata Municipal Corporation or KMC) as our study area. Kolkata is a growing megacity that faces rising pressures on waterenvironmental provision due to the rapid population growth coupled with sporadic urbanization and resultant governance and infrastructural issues despite of having enough water resources (Mukherjee et al., 2018, 2020, 2021).

Increased water use associated with domestic and small-scale industries and real estate business is leading to changes in water supply infrastructure, high rates of groundwater use, and new water conveyance networks in Kolkata (Mukherjee et al., 2018). Poor and inadequate living conditions and municipal services expose to lethal health and sanitation issues (Douglas, 1983). These problems are especially critical in socially deprived areas, commonly known as slums, basti and squatters, within the city or in fringe areas (Kundu, 2003; Mukherjee et al., 2020). Despite of the fact that the right to water and sanitation was recognized as a human right by the United Nations General Assembly on 28 July 2010 (UN, 2010) and recognized by UN's sustainable development goal 6 (SDG) (Mukherjee et al., 2020), social inequities in (mega)cities like Kolkata play an important role in water and sanitation-related risks. With informal settlements and socially deprived areas generally having lower levels of UWS than other parts of the city (WHO, 2020). Marginalized groups, which include women, children, refugees, indigenous people, disabled people, and many others, are often overlooked, and sometimes face discrimination, as they try to access and manage the safe water they need (Mukherjee et al., 2020). For example, gender roles and relations can be important as an explanatory factor to analyze how access, needs, and use of water are shaped in every society (Wallace and Coles, 2005; Ray, 2007). Risks associated with water are higher among women and transgender people in comparison to their male counterpart (Denton, 2002; MacGregor, 2009; Demetriades and Esplen, 2010). Insecurity related to water includes vulnerability due to natural disasters like floods and droughts. In addition, it influences and is influenced by socio-economic pressures-which leads to increased water insecurity for marginalized groups, including women, girls, and trans individuals (Saravanan, 2010). The transgender and other gendered communities, despite of accordion of the Supreme Court of India in 2014, the community is still waiting for genderneutral public toilets (Gopalakrishnan, 2016). Pangare (2016) argues that water security for the poor cannot be achieved without considering socio-economic factors as a determining issue (Pangare, 2016; WWAP, 2019).

\section{Urban Water Security Assessment so Far}

Previous studies in different disciplines have highlighted that vulnerabilities and experiences of UWS vary according to a range of bio-physical and socio-economic factors (Mukherjee et al., 2021). UWS in relation to population size and growth has been the focus of many studies from the 1990s (Vörösmarty et al., 2000; Cook and Bakker, 2012). Most recent studies have demonstrated the development of numerous definitions and assessment frameworks for UWS over the past decade (Denton, 2002; Lundqvist et al., 2003; MacGregor, 2009; Demetriades and Esplen, 2010; Vorosmarty et al., 2010; Sullivan, 2011; Truelove, 2011; Aihara et al., 2015; Muller, 2016; Pangare, 2016; RomeroLankao and Gnatz, 2016; Thompson, 2016; Harris et al., 2017; Hellberg, 2017; Allan et al., 2018; Castán Broto and Neves Alves, 2018; Shrestha et al., 2018; van Ginkel et al., 2018; Aboelnga et al., 2019, 2020; Sultana, 2020). It is proven that UWS is driven by a complex set of biophysical and social factors - which needs to be dealt with together, rather than independently. However, there is still no agreed-upon understanding of how to hypothesize and quantify an assessment framework to measure the current state and the complex dynamics of UWS particularly at the urban level (Mukherjee et al., 2021). This research tries to fill this gap.

The existing measurement frameworks of UWS have been conceptualized in various ways; some focus on risks, while others have adopted broader aspects with a focus on the management of water as a resource for fulfilling human needs only (Clement, 2013; Garrick and Hall, 2014; Giordano, 2017). Several studies have stressed the lack of quantitative and comprehensive assessments of UWS and applications that can be used at the micro level (Grey and Sadoff, 2007; Cook and Bakker, 2012; Srinivasan et al., 2017; Mukherjee et al., 2021). Moreover, some studies show that given the difficulties and shortcomings, such as lack of updated legal tenures, socio-cultural exclusion, and inadequate survey reports, associated with accurately measuring the proportion of the population without access to clean and safe water, it is probable that the proportion thought to have access is grossly overestimated (Nganyanyuka et al., 2014; Satterthwaite, 2016; Adams, 2017). This lack of accurate data on access to clean and safe water indicate the considerable disparity in dynamics of UWS to address urban water challenges effectively and provide decision-makers with robust policy instruments and measures to achieve UWS from the bottom-up approach (Rouse, 2013; Allan et al., 2018). It is therefore important to improve the assessment frameworks to better understand disparities in everyday wateraccess and practices across different scales especially for all in an urban setup.

The approaches of quantitative index-based assessment and the corresponding dimensions and issues of urban 
water mentioned in the previous studies are summarized in Appendix A of the electronic Supplementary Material. This list shows that any attempt to assess UWS needs to consider the intersecting characteristics of bio-physical environment, society, and communities together along with social, economic, ethnic, religious, caste, gender sexuality characteristics-to ensure inclusion across divisions and levels of insecurity (Sullivan, 2011; Truelove, 2011; Thompson, 2016; Harris et al., 2017; Hellberg, 2017; Castán Broto and Neves Alves, 2018; Sultana, 2020).

\section{Aims and Objectives of the Study}

This study aims to assess UWS from a quantitative bottomup approach. We will include the factors behind the multiple intersections in Kolkatas, India, covering one of the world's most densely populated areas, characterized by complex inherited social structures characterized by diverging communities and religious groups (Mukherjee et al., 2018, 2020). The approach sheds lights on the complexity and interconnectedness of water security issues. For example, we want to carve out, how water access issues for multiple social identities at the micro level (i.e., intersections of caste, gender, and socio-economic status) correspond with macrolevel structural factors (i.e., poverty, racism, and sexism) to produce unequal accessibility to water in Kolkata. Therefore, the objective of this study is to develop a quantitative assessment index within the framework of water (in)security in urban areas that can capture the complex interrelationships present between bio-physical and social dimensions (for details see Mukherjee et al., 2021) within water security.

\section{STUDY AREA}

Kolkata city $\left(22^{\circ} 28^{\prime} 00^{\prime \prime}-22^{\circ} 37^{\prime} 30^{\prime \prime} \mathrm{N}\right.$ and $88^{\circ} 17^{\prime} 30^{\prime \prime}-88^{\circ} 25^{\prime} 00^{\prime \prime}$ $\mathrm{E}$ ) is the capital of the state of West Bengal (Figures 1, 2) situated on the east bank of River Hugli in the deltaic Bengal Basin developed by the action of the Ganga-Brahmaputra River system and nearly $120 \mathrm{~km}$ away from the Bay of Bengal. The city area as governed under Kolkata Municipal Corporation (KMC) covers about $205 \mathrm{~km}^{2}$ and is divided into 16 boroughs or administrative blocks, having 21 assemblies and 3 parliamentary constituencies and 144 wards. Population counts 4,496,694 inhabitants and a population density of $24,760 \mathrm{~km}^{-2}$. The ratio of the population is 956 females for every thousand males; the literacy rate is $81.31 \%$. Every day, about 6 million people (floating population) come to Kolkata for work, business, and other purposes (Mukherjee et al., 2021). Within the KMC area, there are little more than 1 million households (KMC report, 2012a). The Census-2011 of India shows that one third of the total population of KMC live in semi-permanent houses within 5,600 (c. 1.141 million residents) deprived areas often referred to as slums (officially known as "basti") comprising a total area of $25.95 \mathrm{~km}^{2}$ (Mukherjee et al., 2020). We have carried out in depth analysis focusing socially excluded areas, often defined as "slums," elsewhere (see Mukherjee et al., 2020). Hence, we exclude the repetition in this research article. In this paper, we aim to have an inclusive approach for which we took the entire survey sample across various socio-economic (i.e., gender, religion, caste etc.) and spatial demographic variations within the study area (i.e., KMC area) as representative population, where "slums" and other "non-slums" households were given equal priorities for analyses. Most of these houses do not have direct piped water supply or toilets (Mukherjee et al., 2020). The number of public toilets in whole KMC area totals 375 of which. The statistics of boroughs of KMC are given in Appendices B, C. Mukherjee et al. (2018) documented detailed bio-physical and social characteristics of Kolkata city and its water security issues. Figure $\mathbf{2}$ emphasizes the importance of looking at intra city variations when it comes to analyzing water security issues, exemplified by variations of gender inclusive public toilets and the number of basti in the different wards of the city. These maps outline the background and a starting point for our analysis as we see how social issues, like population density and the existence of $\mathrm{WaSH}$ facilities, for example, are related.

\section{METHODS}

\section{Data}

\section{Primary Data: Household Survey}

The primary data is based on a household survey using Stratified Random Sampling method. Data were collected from 45 households from each of the Boroughs of Kolkata Municipal Corporation (KMC) area. Altogether 720 households were surveyed within November-December 2018.

Based on the definition of "Water Security" by Grey and Sadoff (2007), this study constructs an Urban Water Security assessment framework to score 4 major components of water security: water availability, water accessibility, water quality and water risks and hazards. The details of each variable are given in the Appendix D.

The Survey questionnaire (Appendix D) forming the basis of the household survey consists of 47 questions divided into 5 segments. The first four segments cover different components of water security (Water Availability: 11 questions, Water Accessibility: 8 questions, Water Quality: 2 questions, and Water Risks and Hazards: 11 questions). The last segment includes demographic data (16 questions) assemblage to reflect the social aspects of water security in the city's neighborhood which includes information on socioeconomics such as income, literacy, gender, religion, and ethnicity (based on language spoken) statistics.

The four components of water security cover all relevant aspects of the integrated urban water security index (Grey and Sadoff, 2007; Mukherjee et al., 2021) as well as, together with socio-demographic indicators form the assessment framework of urban water security within Kolkata Municipal Corporation area. We combined environmental (bio-physical) and socioeconomic indicators (Hoekstra, 2000; OECD, 2016) for each of the water security components, which grouped first into the water security component-scores (at the respondent level) and then aggregated into ward level scores and finally averaged into brough level scores to create the Urban Water Security Index at the borough level.

Due to the ethnic and linguistic diversity of Kolkata, interviewers with a range of language spoken, socio-economic, and ethnic background were recruited, allowing us access and 


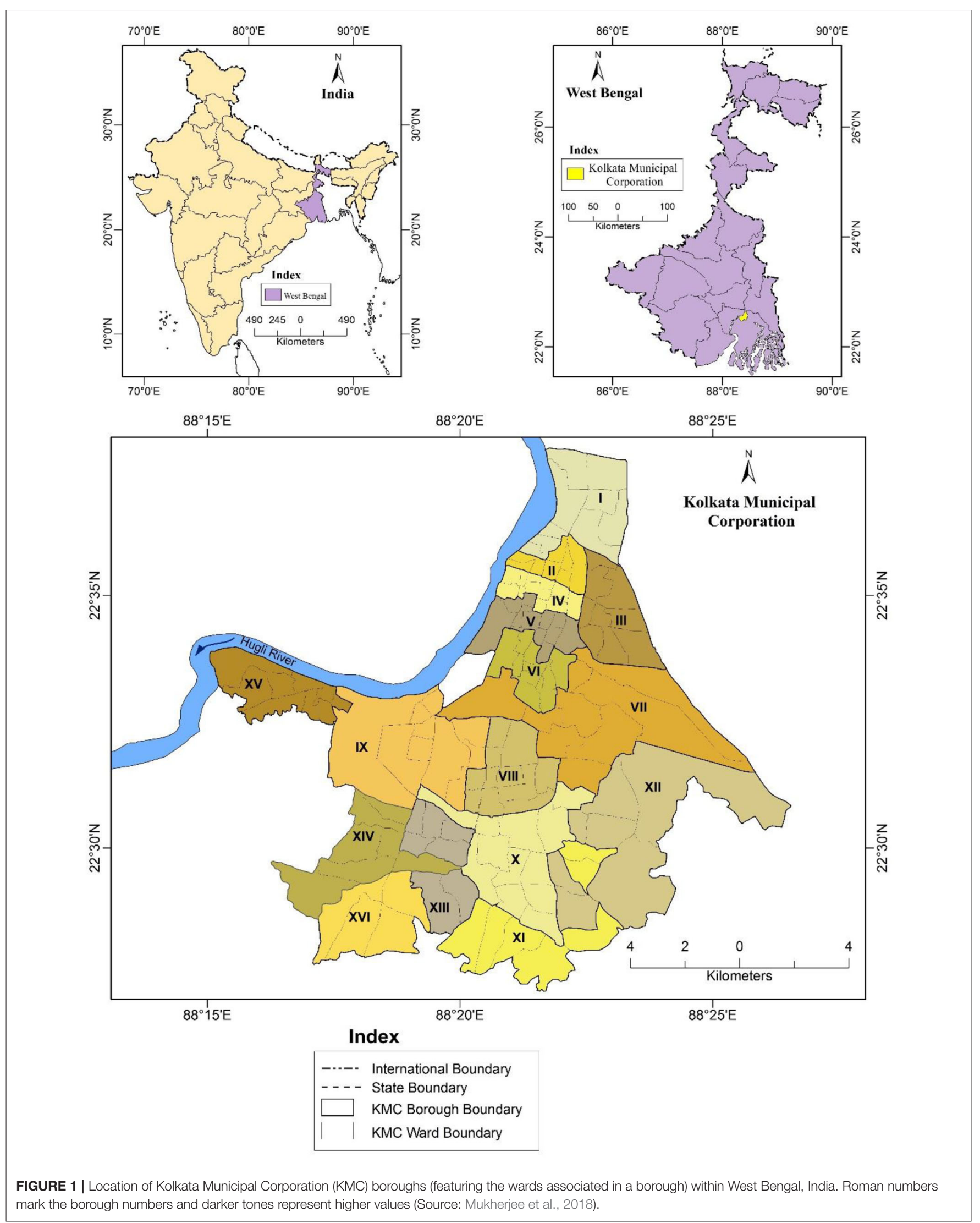




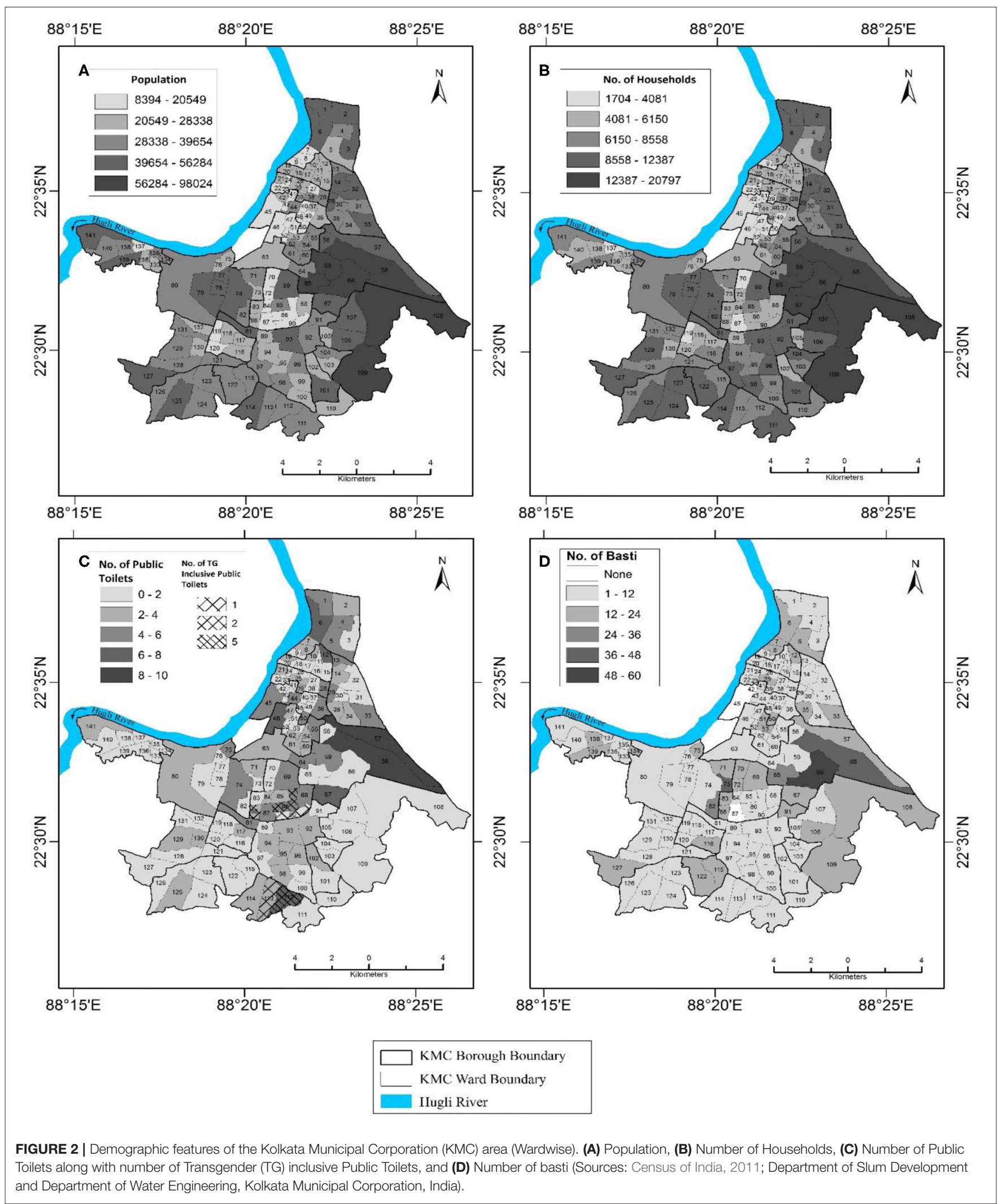


higher levels of rapport with respondents who we otherwise would not have been able to interview due to distrust with members of higher caste/different ethnicity etc. Any time a suitable sample is used, it may confound the analysis because subjects were chosen based on availability rather than being representative of the full population. The interviewers undertook training to ensure they learnt about the crucial (both bio-physical and social) dimensions of water security. Further, they were trained how to avoid biased language as well as ethical issues that may arise during an interview. Survey training activities were particularly important to maintain survey quality and gender sensitization because our survey included the entire gender spectrum to be notified on record. Interviews were conducted based on the availability of respondents, which might affect how representative the sample is. The average survey response rate across the city was about $80 \%$ which varied across the study area.

\section{Secondary Data}

Secondary data were collected from the Department of Water Investigation and Department of Urban Development of Government of West Bengal (data on amount of treated water, urban water supply, distribution, and infrastructures). Additionally, the data from the Kolkata Municipal Corporation (KMC) (Department of Slum Development, Department of Water Engineering) (data on "Slum" population, housing and public toilets), West Bengal Pollution Control Board (WBPCB) (data on surface water quality) and Kolkata Municipal Development Authority (KMDA) were also collected (data on groundwater quality, urban water supply and distribution network at the boundary areas of Kolkata Municipal Corporation). These data contained information on the components of water security within Kolkata Municipal Corporation (KMC) area.

\section{Data Processing Initial Data Processing}

We assigned variables' scores on a 0 -10-point scale of water security, where 0-2 denotes "Very Insecure," 2-4 denotes "Insecure," 4-6 denotes "Around acceptable threshold" and 8-10 denotes "Very Secure" state of UWS). These categories and cut off values for security status were based on the "urban water security dashboard" proposed by van Ginkel et al. (2018). Here, 5 (median value between 0 and 10) is considered as the "threshold" point. Therefore, score higher than 5 denotes secure status of UWS and lower than 5 indicates insecure status of UWS. Aggregation from each level to the next was done by calculating the arithmetic mean. Finally, the borough level scores of the four components of water security were further combined into one water security index (borough level), which determined the final ranking of the KMC boroughs.

\section{Principal Component Analysis}

Principal Component Analysis (PCA) allows us to identify patterns and components that enhance our understanding of water security (Raschka, 2015). In this case, it helps us to identify which factors come together to create the crucial components of water security, and then allowing us to create an index to measure it (Aihara et al., 2015; Shrestha et al., 2018). Each of the PC axis or factors (with high loadings on one or more variables) may be representing an independent source of variation in the data (Vyas and Kumaranayake, 2006). The first principal component is selected as the linear index of all the variables that captures the largest amount of information common to all the variables which may then be used as the index (Filmer and Pritchett, 2001). This approach allows the determination of the most appropriate weightings for each variable to derive an index which captures maximum variation (Filmer and Pritchett, 2001; Vyas and Kumaranayake, 2006; Raschka, 2015; Shrestha et al., 2018).

\section{Calculation of Urban Water Security Index}

Urban Water Security Index (UWSI) scores have been calculated integrating scores of variables of Water Availability, Water Accessibility, Water Quality, and Water Risk and Hazards variables from the survey data collected across the city. Here the objective is to analyse the interrelationship between UWSI scores and socio-demographic parameters (such as gender, religion, monthly income, caste, ethnicity, occupation, education, and household type) within boroughs across the city.

The Urban water security index (UWSI) at the borough level was calculated as:

$$
\mathrm{UWSI}=\left(\mathrm{Avl}^{*} \mathrm{w} 1\right)+\left(\mathrm{Acs}^{*} \mathrm{w} 2\right)+\left(\mathrm{Wqt}^{*} \mathrm{w} 3\right)+\left(\mathrm{Wrh}^{*} \mathrm{w} 4\right)
$$

Where,

Avl = Score for Water Availability variables

Acs $=$ Score for Water Accessibility variables

$\mathrm{Wqt}=$ Score for Water Quality variables

$\mathrm{Wrh}=$ Score for Water Risk and Hazards variables, and,

w1, w2, w3, w4 are the weights assigned (determined by the "loadings" of PCA 1) for each variable.

Finally, the UWSI scores were used to categorize each borough on the 0 -10-point scale (Status of security status as discussed earlier) classifying the status of urban water security.

\section{Interrelationships Between UWSI and Socio-Demographic Variables}

Indicator scores were aggregated to an Urban Water Security Index (UWSI) at the borough level, (we preferred borough level index to be able to access to government data at the borough level than that of 144 wards). We then studied the coherence between UWSI's scores and the sociodemographic characteristics of the Kolkata Municipal Corporation area, through statistical analyses (Pearson's correlation and crosstabs-contingency tables) using SPSS.

\section{RESULTS}

\section{Principal Component Analysis}

The aggregated values of the four water security components were analyzed using Principal Component Analysis (PCA), and four principal components (PCs) were identified. The choice of 4 components was based on each of the PCs explaining data variation between 13.02 and $36.23 \%$ and accounting for $100 \%$ of the total variance (Table 1 ). In the analysis of the variables 
TABLE 1 | Total variance explained.

\begin{tabular}{|c|c|c|c|c|c|c|c|c|c|}
\hline \multirow[t]{2}{*}{ Component } & \multicolumn{3}{|c|}{ Initial eigenvalues } & \multicolumn{3}{|c|}{ Extraction sums of squared loadings } & \multicolumn{3}{|c|}{ Rotation sums of squared loadings } \\
\hline & Total & $\%$ of variance & Cumulative \% & Total & $\%$ of variance & Cumulative \% & Total & $\%$ of variance & Cumulative \% \\
\hline 1 & 1.45 & 36.23 & 36.23 & 1.45 & 36.23 & 36.23 & 1.43 & 35.72 & 35.72 \\
\hline 2 & 1.10 & 27.58 & 63.82 & 1.10 & 27.58 & 63.82 & 1.12 & 28.10 & 63.82 \\
\hline 3 & 0.93 & 23.16 & 86.98 & & & & & & \\
\hline 4 & 0.52 & 13.02 & 100.00 & & & & & & \\
\hline
\end{tabular}

Extraction method: principal component analysis.

TABLE 2 | Communalities.

\begin{tabular}{lcc}
\hline & Initial & Extraction \\
\hline Water availability & 1.000 & 0.742 \\
Water accessibility & 1.000 & 0.738 \\
Water quality & 1.000 & 0.614 \\
Water risk and hazards & 1.000 & 0.458
\end{tabular}

Extraction method: principal component analysis.

studied, the resulting first principal component PC1 explained $36.23 \%$ of the data variability, while PC2 explained $27.58 \%$ of the variance. The remaining principal components PC3 and PC4 accounted for $10-20 \%$ of the variance. Communalities statistics revealed that $>70 \%$ of the variance can be explained by the factor Water Availability and Water Accessibility, $>60 \%$ of the variance by the factor Water Quality and $>45 \%$ of the variance can be explained by the factor Water Risk and Hazards (Table 2). This analysis confirms the assumptions of our study that these dimensions are the crucial dimensions of water security, and we go on to look at what social and bio-physical dimensions are associated with higher or lower levels of security along these dimensions.

The UWSI aggregates the components of water security into a single index which represents the set of information collected through survey, and we argue, that this index improves assessment of the multidimensional issues affecting water security. The factors loadings (Table 3) associated with the variables indicate which are the most important of the different water security components in terms of distinguishing between different levels of wellbeing and so which variables the index is most sensitive to Filmer and Pritchett (2001), Vyas and Kumaranayake (2006), Raschka (2015), Shrestha et al. (2018). These factor loadings are the weights assigned to each variable in Equation 1 to calculate UWSI values. Water Availability (0.837) and Water Risk and Hazards (0.667) show the highest factor loadings and are the highly correlated with the first principal component PC1; correspondingly, they are the best single-dimensional descriptors of the dataset. As the data have been scaled and centered, the resulting principal components and index of values based on this component are all relative values enabling comparisons, however their absolute values without validity (Tables 1-3). In contrast,
TABLE 3 | Factors loadings (rotated component matrix) of the first and second principal components.

\begin{tabular}{lcc}
\hline & \multicolumn{2}{c}{ Principal component } \\
\cline { 2 - 3 } & $\mathbf{1}$ & $\mathbf{2}$ \\
\hline Water availability & 0.837 & 0.204 \\
Water risk and hazards & 0.667 & -0.113 \\
Water accessibility & 0.332 & 0.792 \\
Water quality & -0.416 & 0.664 \\
\hline
\end{tabular}

Extraction method: principal component analysis. rotation method: varimax with kaiser normalization ${ }^{\text {. }}$

${ }^{a}$ Rotation converged in 3 iterations.

the variables which were less important in the index still contributed to the distinction, including Water Accessibility (0.332) and Water Quality (-0.416), which is why we still include them.

\section{Spatial Distribution of UWSI Values}

After calculating UWSI values using the weights of PC1, the results were tallied with individual water security component scores to compare with UWSI. Distribution of scores of UWSI values in comparison to scores of the components of water security within Kolkata Municipal Corporation (KMC) area at the respondent level (Figure 3) shows the scores of UWSI (mean $=7.33$; median $=7.33$; Interquartile Range $\mathrm{IQR}=$ 8.56-6.20); data are normally distributed without skew and fall into the range of status of water security within Kolkata Municipal Corporation area. Skewed data distribution occurs for the UWS components: For Water Availability, data is right-skewed $($ mean $=4.60$; median $=4.43$; IQR $=5.33-$ 4.08), whereas Water Quality data has the highest variability in scores among all the water security components and is potentially left-skewed (mean $=6.72$, median $=7.37$; IQR $=$ 5.65-7.70). Water Accessibility (mean $=4.88$; median $=$ 4.91; IQR $=5.34-4.50)$ has a low variability and falls into the range of "Around acceptable threshold." Water Risk and Hazards (mean $=6.99$; median $=7.11 ; \mathrm{IQR}=6.55-7.70)$ ranges within the "Secured" status of water security and having almost identical mean and median. From this we can see the importance of disaggregating the index to understand which component is driving and influencing the overall averages, here we see the overall higher mean of Water Risk and Hazard, 


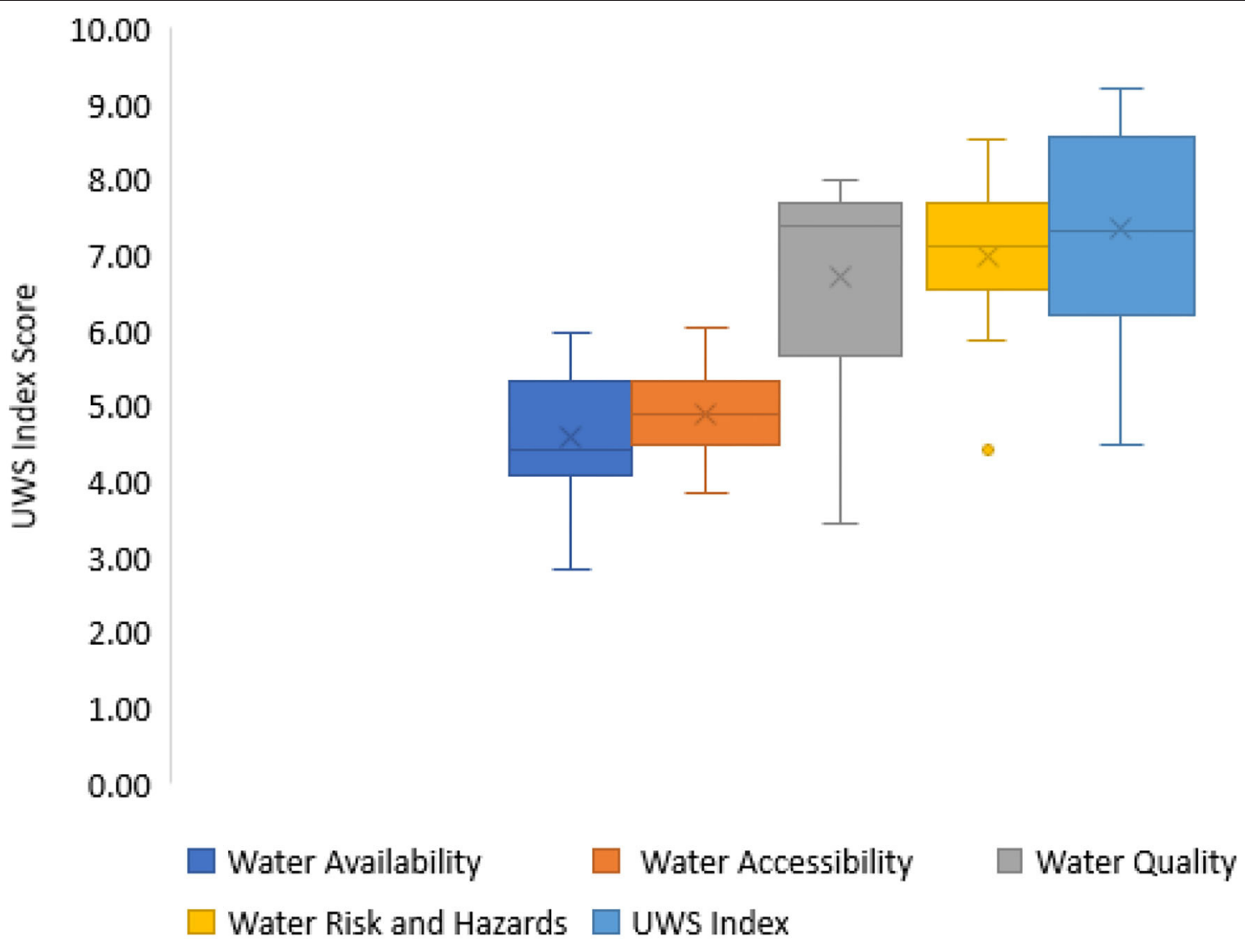

FIGURE 3 | Distribution of scores of Urban Water Security (UWS) Index (along the Y-axis) and Components of Urban Water Security (Water Availability, Water Accessibility, Water Quality, and Water Risks and Hazards) (along the X-axis) within Kolkata Municipal Corporation (KMC) area at the respondent level. Data source: Survey data.

compared to lower overall "security" along Water Accessibility and Water availability.

Further delving into the components of the UWSI index, we find that (Water Availability, Water Accessibility, Water Quality, and Water Risks and Hazards) (Figure 4) the scores for Water Availability and Water Risks and Hazards played a major role in the overall status of the UWS of the boroughs, thus explaining the overall high mean and median for the UWSI. High values of Water Risks and Hazards component dominate the final index scores for all the boroughs. Figure 4 highlights the intra city variations across the components and underlines the need for researchers to take intra city variation into account when studying water security. For the Water Risks and Hazards component, boroughs VIII and XV show highest UWSI scores within Kolkata Municipal Corporation (KMC) area (borough VIII $=9.21$, borough XV $=9.05$ ). For borough VIII, both Water Risks and Hazards and UWSI score are $>8$. For borough XV, UWSI score is higher than 9 despites of the score for Water Quality amounts 3.44 which means "Insecure." Scores of Water Quality component have no impact on the total UWSI scores for boroughs IX and X. These boroughs show the lowest scores in Water Quality within Kolkata Municipal
Corporation (KMC) area (boroughs IX $=5.11$ boroughs $\mathrm{X}$ $=3.66$ ), but the urban water security status for borough IX and X are still "secured" because of the higher scores in Water Risks and Hazards. In borough VI the value for the Water Quality component totals 7.89, however, due to its low score in Water Availability (3.65), it only receives an "Around acceptable threshold" status of UWS. For borough XIII UWSI score (4.48) is ranked as the lowest within Kolkata Municipal Corporation (KMC) area, coinciding with the lowest score in Water Availability (2.85).

Figure 5 shows borough wise distribution of \% of respondents with different status of Urban Water Security (UWS) across the Kolkata Municipal Corporation (KMC) area. The highest percentage of respondents projected as "Very Secured" status of UWS are in borough VIII (>86\%). Borough I has the maximum respondents with "Secured" status. No respondent in borough VI and XIII is falling within "Very Secured" status of UWS. More than $2 \%$ of respondents within borough XIII are falling into "Very Insecure" status of UWS and this is the only borough which has respondents with "Very Insecure" status of UWS. Most respondents (39.16\%) within the whole survey dataset are falling within "Very Secured" status of UWS. Boroughs I, IV, VIII, IX, 

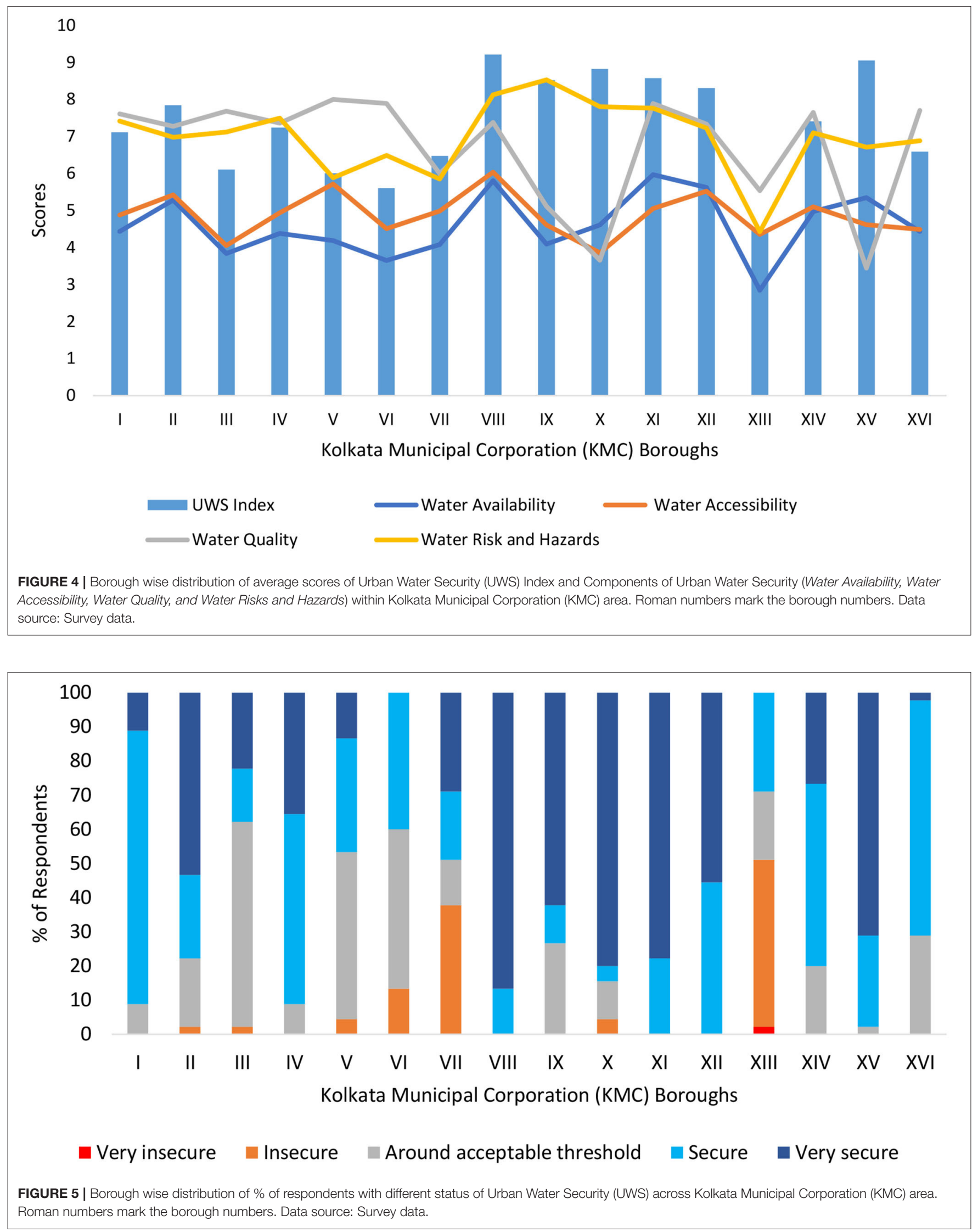
XI, XII, and XV-XVI have no respondent with either "Very Insecure" or "Insecure" status of UWS.

As seen in Figure 5, another crucial factor to take into account is highlighted when we look at intra borough variation of the UWS components.

Looking at the geographical distribution of the components of UWS (Water Availability, Water Accessibility, Water Quality, and Water Risks and Hazards) we can better appreciate how they vary across boroughs in the KMC area (Figure 6). For Water Availability, no borough has entirely either "Very Secure" or "Very Insecure" status of UWS. Most boroughs have "Secure" status, except boroughs IX, XIV, and XV where the UWS status is limited to "Around acceptable threshold." Borough XV has the same "Around accepted threshold" status of UWS for Water Accessibility scores, where borough I is in the "Very Secured" status. The rest of the boroughs are "Secured" with Water Accessibility. Variations are also less for Water Risks and Hazards component of UWS across KMC. In this case, boroughs XIV and XVI are within "Around accepted threshold" status and broughs I, II, and III are in "Very Secure" status of UWS, where rest of the boroughs are having "Secure" status for Water Risks and Hazards. Borough wise scores for Water Quality vary more than other components of UWS across the entire KMC area. Boroughs IV and XIII are within "Very Secure" status, boroughs II, III, and VII are within "Around accepted threshold" status and the rest are in "Secure" status of UWS.

By using borough wise UWS index scores we can observe the combined effect all component of UWS across the KMC area (Figure 7). The UWS index scores appear to be within "Secure" status for the boroughs I-V and VII in the north-central part of KMC area and boroughs XIV and XVI in the southern part of KMC area. For boroughs VI and XIII, the UWS index scores fall within the "Around accepted threshold" status. However, boroughs VIII-XII and XV in the southern part of KMC fall within "Very Secure" status of UWS.

\section{Interrelationships Between Index Values and Socio-Demographic Variables \\ Pearson's $r$}

We calculated Pearson correlation coefficients to assess the strength and direction of correlations between sociodemographic variables (Independent variables), urban water security (UWS) components (Water Availability, Water Accessibility, Water Quality, and Water Risks and Hazards) and the UWS Index (Dependent variables) (Table 2) within the Kolkata Municipal Corporation (KMC) area. There are statistically significant correlations in the data between the UWSI values with all the components of water security variables along with type of households, number of members in the households, caste, and employment status of the respondents $(\alpha$ $<0.01$ ) (Table 4). UWSI values also correlate with Ethnicity $(\alpha<$ 0.05). Water Availability component of UWS shows statistically significant correlations with other UWS components and types of households, monthly household income, caste, ethnicity, occupation, gender, and the education levels of the respondent and other family members. Gender of the respondent also correlates with the Water Quality and Water Risks and Hazards components of UWS $(\alpha<0.01)$. Employment status and religion of the respondent only correlate with Accessibility component of UWS $(\alpha<0.01)$. There are statistically significant relationships between Accessibility component of UWS and education level of the respondent, Water Quality variables and types of households, education levels of both the respondents and their family members $(\alpha<0.05)$. Castes of the respondents statistically corelate with all the components of UWS. Number of members in the household and Water Risks and Hazards also have a statistically significant relationship $(\alpha<0.01)$. The survey data do not provide statistically significant relationships between the dependent variable UWSI scores and the independent variables such as monthly household income, religion, occupation, employment status, gender, and the education levels of the respondents $(\alpha>0.05)$. High income, caste, education, and occupational level correlate with higher levels of UWS. Furthermore, religion, ethnicity and gender also matter as being a Hindu, Bengali speaker and cis-man is associated with higher UWS.

\section{Cross Tabulation}

The Cross tabulation of survey data (Appendix E) reveals the percentages of respondents based on its different sociodemographic characteristics (such as caste, ethnicity etc.) within different categories of UWSI scores (Very Insecure to Very Secure) as shown by the bivariate analysis in the previous section (chapter 4.3.1). The main findings from the cross-tabulation analysis are as follows:

\section{Household Types}

Respondents having their own house constitute the majority in the Very Secure status of UWS. In contrast, respondents dwelling in semipermanent houses in deprived areas are found in the Very Insecure status of UWS.

\section{Monthly Household Income}

Forty seven percentage of the respondents from the higher income group (monthly income $>25,000$ INR), $33.3 \%$ of the respondents from the middle income (monthly income 10,00025,000 INR), and $16.7 \%$ of the respondents from the lower income group are within the Very Secure status of UWS. However, the remaining respondents from the lower income group are within the Very Insecure status of UWS.

\section{Caste}

$86.2 \%$ of the respondents from general (upper) caste and $13.8 \%$ of the respondents from scheduled caste/scheduled tribes/other backward castes (SC/ST/OBC) are within the Very Secure status of UWS. Respondents from general caste are the majority $(86.2 \%)$ in the Secure status of UWS than the SC/ST/OBC (12.9\%) respondents.

\section{Ethnicity Based on Languages Spoken}

$81.9 \%$ of Bengali speaking respondents and $17.4 \%$ of Other Indian languages speakers are in the Very Secured status of UWS. Conversely, $0.3 \%$ of Bengali speakers, and $0.8 \%$ of total Other 

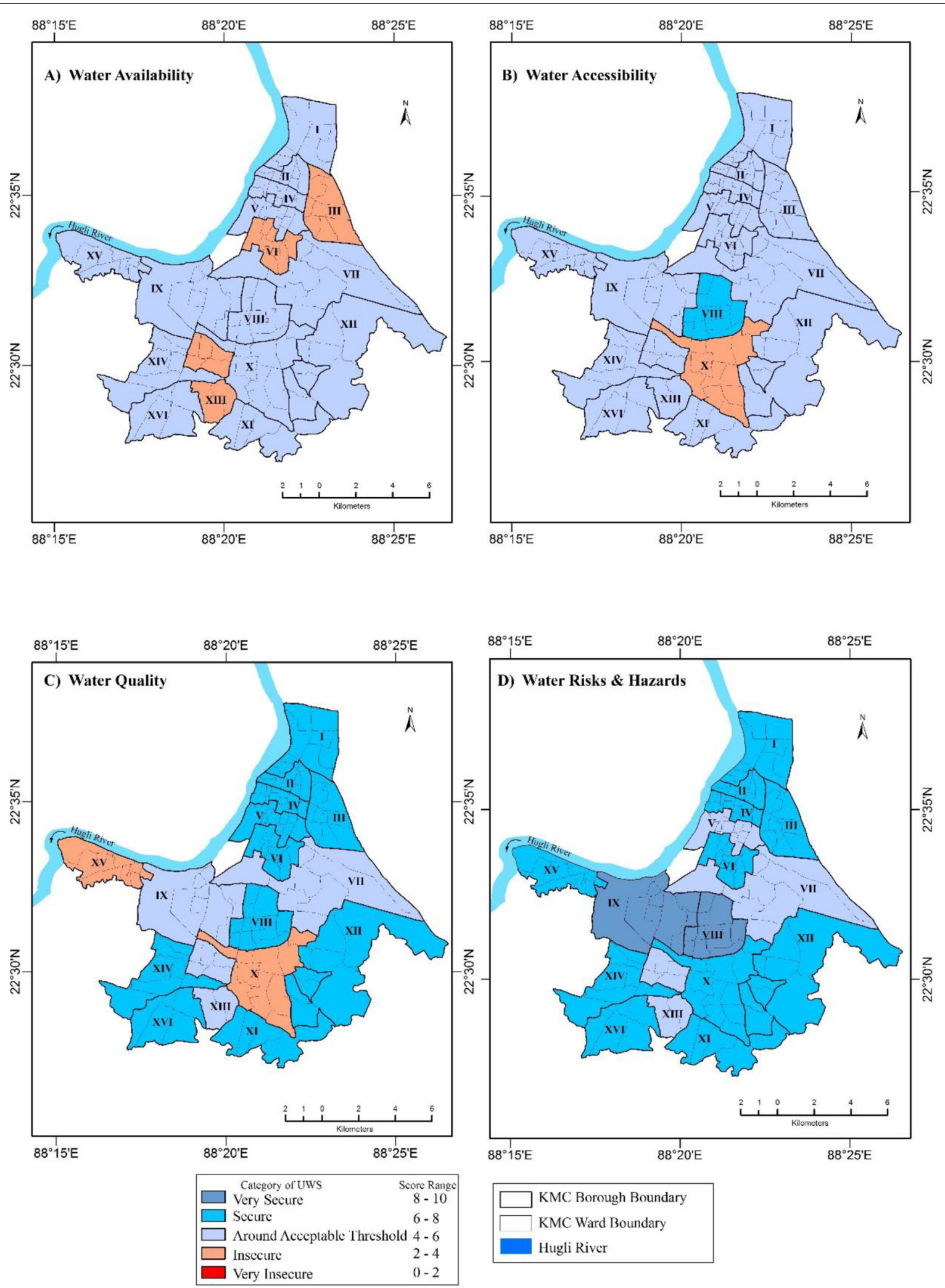

FIGURE 6 | Urban Water Security (UWS) status associated with each component [(A) Water Availability, (B) Water Accessibility, (C) Water Quality, and (D) Water Risks and Hazards] of UWS within each borough of Kolkata Municipal Corporation (KMC) area. Roman numbers mark the borough numbers. Data source: Survey data. 


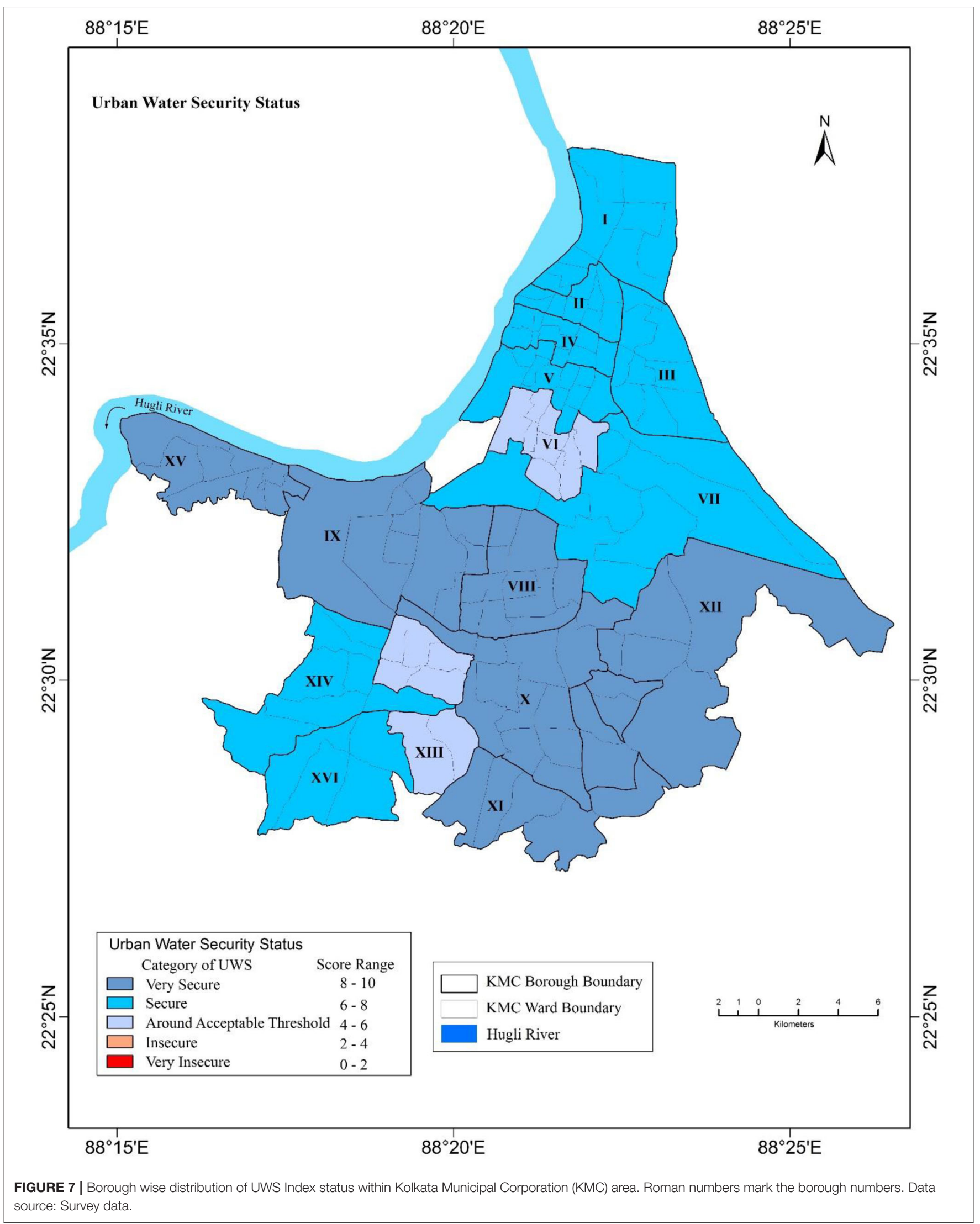




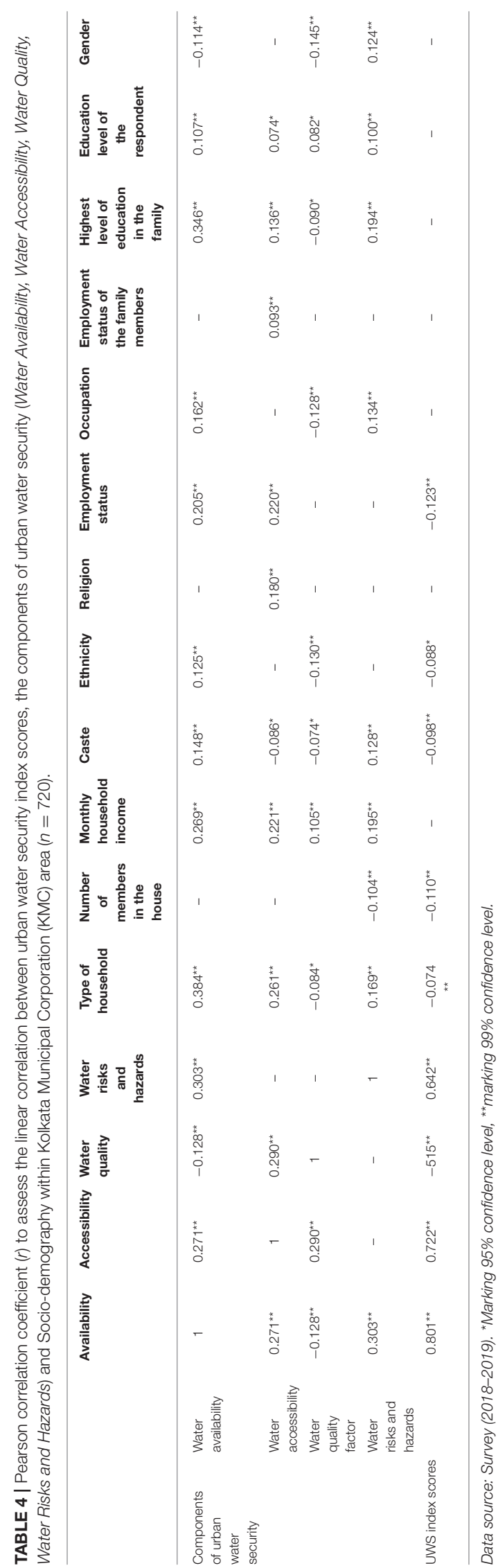

Indian language speakers are within the Very Insecure status of UWS.

\section{Religion}

83.3\% of Hindu respondents and 11.6\% Muslim respondents are having Very Secure status of UWS. In contrast, Insecure status of UWS is higher among Muslim respondents (40\%) than Hindu respondents (10\%).

\section{Occupation}

Respondents who do household works are the most water secured ones, while students and those working in unorganized business/jobs are the least water secured respondents.

\section{Level of Education}

$34.7 \%$ of the respondents with a college/bachelor's degree have the Very Secure status of UWS, while only $2.9 \%$ of the Postgraduate degree holders are the least water secured.

\section{Gender}

Within the Very Secure status of UWS, 37.7\% of cis-males build the majority. Simultaneously, $9.6 \%$ of cis-female, $5 \%$ of intersex, $13.2 \%$ of cis-male, and $13.7 \%$ of trans(gender) respondents are within the Insecure status of UWS, while $0.8 \%$ of the cis-male respondents and $0.9 \%$ of the trans(gender) respondents are within the Very Insecure status of UWS.

\section{DISCUSSION}

This research quantifies the spatial distribution of urban water security (UWS) of Kolkata city through a novel index-based assessment framework that encapsulates both bio-physical and social dimensions. In this discussion section, we discuss the explanations and factors driving the spatial variations of UWS index scores, based on the individual components as well as the overall scores of the quantified UWS index and their interrelationships. This section also discusses the study area specific findings from the UWS index, despite of the current limitations of the quantitative assessment framework, how megacities in emerging economies such as Kolkata suffer from intrinsic water insecurity even when their advantageous location and resource-abundance (Basu, 2016; Mukherjee et al., 2018) in terms of water seem to be "secure" (van Ginkel et al., 2018). Variations in individual components of Urban Water Security (UWS) are discussed in the following sections: water availability, water accessibility, water quality, and water security.

\section{Water Availability}

Water Availability corresponds to sufficient and continuous water supply for personal and domestic uses, including drinking and other domestic purposes (Gleick, 2004; Mukherjee et al., 2020). Based on our findings Water Availability varies across boroughs and wards in KMC and is varying around what has been set as an "acceptable" threshold. The lower range of Water Availability indicates that there is a demand for supply of potable water, in particular in some areas of KMC, namely the southern peripheral boroughs such as boroughs XIII-XIV (Figures 1, 2; Appendices B, C). 
The water supply system of KMC has been in operation since 1865. The average per capita supply is 134 liters per capita per day (lpcd), which is near to desired supply of 150 lpcd (for metropolitan cities). Nevertheless, the supply is very uneven, ranging from 310 to $40 \mathrm{lpcd}$ with an average supply period of $8 \mathrm{~h}$ a day. The water supply system for KMC area is mainly based on water of River Hugli after treatment, where $92 \%$ of the total households within the whole KMC area are connected with direct piped supply (Mukherjee et al., 2018). This estimation does not include the semi-permanent households of the deprived areas of KMC, where around 35\% of KMC's population lives without having direct piped supply of potable water. The daily water demand is estimated as 293 million liters per day as per 2012 , where the total daily treated water supply capacity of the 4 treatment plants of Kolkata is 271 million liters per day. Nevertheless, age-old water pipelines cause high water loss in distribution (ADB, 2011; KMC report, 2012b; Mukherjee et al., 2018). It is also accounted that $35 \%$ of the water is wasted everyday due to the leakage in pipes (Basu, 2016; Mukherjee et al., 2018). As a result, there are gaps in demand-supply which we see as one of the drivers for the low scores of Water Availability component. Another issue is disparity of distribution of piped supply throughout the entire KMC area. Most of the direct supply of treated water is seized by middle and upper strata of the society which also include bigger commercial establishments. Therefore, disparity can be evident in Water Availability of water among different sections of society within KMC.

The resultant effect of urbanization within and around KMC area increased demand of water put pressure on groundwater resources. Around, $10-15 \%$ of KMC's potable water supply is sourced from groundwater which covers up to $30 \%$ of the potable water used in households (KMC report, 2018). There are around 439 big diameter tubewells fitted with motor-pump and 10,050 small diameters tubewells fitted with handpump within KMC area, which exclude the numbers of "unaccounted" tubewells installed and used by the large housing complexes (Chatterjee, 2014). Issues associated with unplanned, excessive, and "unaccountable" groundwater extractions are land subsidence, depletion of groundwater level, and aquifer contamination (Sahu et al., 2013; McArthur et al., 2018; Hati et al., 2020). Absence of water meters or penalty system also encourage this unaccountable groundwater extraction (Mukherjee et al., 2018; Hati et al., 2020).

Other important aspect of urban water availability is the declining inland surface waterbodies (urban wetlands such as canals, ponds, or constructed inland fresh waterbodies) and their littoral zones due to urbanization (Vörösmarty et al., 2000; Moss, 2008; Feng et al., 2010; Veldkamp et al., 2017; Chen et al., 2020). Mukherjee et al. $(2018,2020)$ showed that borough wise declining rate of wetlands was higher in the main city areas whereas the peripheral areas lost comparatively less. Nevertheless, the gross reduction of wetlands in Kolkata and its suburban areas impacted the direct availability (and, accessibility) of freshwater for other household purposes except drinking. These waterbodies were one of the major sources of water for household purposes for the residents of deprived areas (slums) as well as for the lower income groups living in semi-permanent squatters near /on the bank of these waterbodies (Mukherjee et al., 2020). Apart from the human dimension of water supply and groundwater recharge issues (Young, 2015), urban wetlands are also vital for managing the environmental functions, such as controlling flood, pollution and soil erosion and managing microclimate of the surroundings with the relative cooling impact (Forman, 2014; Manteghi et al., 2015; Neelakantan and Ramakrishnan, 2017).

Furthermore, our survey data show that only $67 \%$ households $(n=720)$ within KMC have a toilet inside. According to KMC's report (2012) for Asian Development Bank (ADB), only 44\% of all households within KMC are having toilet facilities. In the derived areas, according to the Census of India (2011), more than $50 \%$ of the total households, 14 to 25 people are having access to only one community toilet (Mukherjee et al., 2020). Four percent of the KMC population had no toilet facilities nearby and used gutters, open drains, canals, or vacant lands instead (KMC report, 2012a). There are 383 public (pay and use) toilets in the KMC area (KMC report, 2018) some of which are having poor quality without necessary sanitation facilities making them useless throughout the year (Mukherjee et al., 2020). Fifty percent of the population of KMC has access to sewerage services (Mukherjee and Ghosh, 2015). A total number of 358,750 households ( $75 \%$ of the total households) within KMC are directly connected to the underground sewer network. The collection efficiency of sewage is $71 \%$. The collection efficiency is around $90 \%$ in the core city area whereas, the remaining peripheral areas have no formal sewer system yet and collection is zero (KMC report, 2018).

\section{Water Accessibility}

Water Accessibility points to the need for adequate and safe water, sanitation, and hygiene (WaSH) facilities to be located or constructed in such a way that they are always accessible to everybody. Safe access to clean water, sanitation and hygiene facilities is particularly important for people with constrained physical movement and marginalized groups who may face safety risks (Wallace and Coles, 2005; WHO, 2018; Mukherjee et al., 2020). Gender, ethnicity, religion, and caste matters when it comes to access and availability to toilets and required WaSH facilities, for example, females stay home and face the tremendous issues with access to WaSH. Provisions of WaSH are crucial factors of water security, maintaining basic health standard. The provision of WASH in health care facilities serves to prevent infections and spread of disease, protect staff and patients, and uphold the dignity of vulnerable populations (WHO, 2015, p. 4).

Our survey revealed that $22.5 \%$ households within KMC did not have any access to WaSH facilities. Our study revealed the importance of deprivation as a factor explaining water security. As, after almost 15 years, in 2018, 42.5\% household in deprived areas had access to WaSH facilities and $32.2 \%$ respondents did not have any WaSH facilities within their accessibility, which can tend to open defecation. This percentage is much higher than the national average, where, according to Census 2011 data, open defecation among the slum dwellers in India was 18\% (Satapathy, 2014; Sau, 2017). This finding also shows the need for better and more accurate data. 
Fundamentally, water is a social good (Day, 1996; Rogers et al., 1998). Therefore, ensuring universal access to water is the most essential element for achieving urban water security (WWAP, 2019). Our results suggest that the most water-secure groups in Kolkata are either cis-gendered or general (upper) caste or more educated or people living in their own houses. Inequalities along the multiple intersecting dimensions of various social categories such as gender, caste, ethnicity and religion are strong in Indian societies, which are now deepened with the emerging prosperity of the country widening the gaps between majority and minorities (Anne et al., 2013). Power politics, livelihood gaps, inherent stigmatization are increasing the gaps in necessities, preferences, and capacities in every segment of citylife (Anne et al., 2013; Shahid and Pelling, 2020). As a result, the intersecting categories, and inter-categorical differences in access to water and sanitation provisions are complex and spatially heterogenous (Fletcher, 2018). These inequalities also include the extremes such as physical-sexual assaults and denial of access to water specially for marginalized groups such as transgender communities (Alston and Whittenbury, 2013; Boyce et al., 2018). Disregarding the essentiality of inclusive (and intersectional) analytical framework may ignore or generalize the existing inequalities in the urban water system (Yuval-Davis, 2006; Valentine, 2007; May, 2015; Fletcher, 2018). Gender issue has already been highlighted in the Dublin Principles (1992) on bridging the gender gap in water resource management and other literatures (Global Water Partnership, 2019). However, the notion of inclusive approach is still lacking its significance in the research and practices raising the concern of basic right to water (Mukherjee et al., 2020), and we have also seen very few studies on gender along a continuum where water security for those outside of the gender binary are considered.

\section{Water Quality}

Water quality must be safe for human consumption (i.e., drinking and other household purposes including cooking) as well as for personal and domestic hygiene. This means the water must be free from germs, chemical substances, and radiological hazards that constitute a threat to a person's health both short term and over a lifetime of consumption (Gleick, 2004; Mukherjee et al., 2020). According to our results, the Water Quality component of UWS of KMC area are significantly related to risks and hazards associated with urban water as well as type of households. The main sources of contamination in the supplied water services with KMC are leakage in the supplypipes (Ghosh, 2002) and seepage from the landfills (Mandal et al., 2019), stormwater discharges containing industrial wastes and uncovered sewage in both surface water and groundwater (Singh et al., 2009). The analyses of the survey data reveal that in KMC, the supply of good quality drinking water is not sufficient and inadequate quality drove most of the total respondents of boroughs II, III, and III away from using the supplied water to find out other sources of water for drinking and other household purposes. These areas of KMC consist of the older parts of the Kolkata city, where the existence of leakage and outlived metal pipes are possible sources of contaminants in water (Chakravarty, 2007; Mukherjee and Ghosh, 2015; Basu, 2016).
Within the KMC, groundwater is susceptible to pollution due to the leakage from the open dumping of domestic and industrial wastes. Therefore, the direct usage of groundwater through both deeper and shallower tubewells and bore wells can have direct and indirect issues of water quality, including dysfunctional colors, odors, and other visible quality issues. Chakravarty (2007), traced the source of contaminants such as mercury $(\mathrm{Hg})$, lead $(\mathrm{Pb})$, cadmium $(\mathrm{Cd})$ and chromium $(\mathrm{Cr})$ in samples taken from tube wells, river Hugli, and piped water within KMC area. The presence of lead $(\mathrm{Pb})$ in river water and drinking water were very much noticeable in almost all the samples in both summer and winter seasons while the presence of chromium has been noticed in river water during monsoon seasons. Presence of mercury during monsoon season has also been detected in samples within KMC (Chakravarty, 2007). Decrease in wetlands and increase in urbanized impervious surface within KMC area are another cause of discharge of wastes into the surface and groundwater systems and increase the pollution (both organic and inorganic contaminants) levels of receiving water (Mukherjee et al., 2021). McArthur et al. (2018) traced in few groundwater samples arsenic concentrations between 10 and $79 \mu \mathrm{g} \mathrm{L}^{-1}$ to a factory site producing Paris Green, an arsenical pesticide manufactured between 1965 and 1985, sporadic lead $>10 \mu \mathrm{g} \mathrm{L}^{-1}$ from wellfittings, many samples contaminated by $\mathrm{Cl}$ from wastewater (sewage and septage) and natural $\mathrm{Mn}>0.3 \mathrm{mg} \mathrm{L}^{-1}$.

\section{Water Risks and Hazards}

Water risks and hazards related issues include mainly floods, water scarcity, water-borne diseases due to the presence of organic and inorganic substances in the water and land subsidence. The changes in land use and land cover (LULC) within the KMC area since 1980 (Mukherjee et al., 2018) resulted in the drainage of wetlands and its replacement by either compact surfaces or barren land for urban development. The shrinkage of surface waterbodies, clearing of the trees in the city increased surface runoff (Kiran and Ramachandra, 1999) and consequently, groundwater level lowered (Hagler, 2007; Mendoza et al., 2011; Ali et al., 2018). According to our results, two boroughs, XIII and XIV, which are situated at the periphery of the KMC boundary and within the reach of Adi Ganga canal remained within "Around accepted threshold" status of UWS. This result establishes the links between deteriorated water quality of Adi Ganga canal and poor and inadequate living conditions, sanitation issues, and lack of municipal services in the canal side temporary/semi-permanent settlements where morbidity and mortality rates are high (Douglas, 1983). These problems are especially critical in socially excluded areas and for squatters in fringe areas (Kundu, 2003). Peri-urban fringe areas (e.g., newly added wards, such as 101, 141-46) are lacking access to piped water supply from the municipality. The residents must either use the groundwater through hand-pumped tube wells or get access from KMC supports such as water delivery by water trucks few times a week. The increasing numbers of people living in these areas have been a key focus for urban planning work in respect to accessibility of safe drinking water and availability of adequate sanitation facilities (Sau, 2017). 
The importance of deprivation in the area of water security cannot be underestimated. During severe flooding, such as in September 1999, the deprived areas of the city suffered from a paucity of power supply, acute shortages of safe drinking water, outbreaks of water borne diseases such as gastro-enteritis, typhoid, entamoebiasis, hepatitis etc. and a long period of water logging (Mukherjee et al., 2018). Palit et al. (2012) conducted a study on the potential of different water sources, both for drinking and domestic purposes, for diarrheal disease transmission in Kolkata's urban slums (Palit et al., 2012). The results show a significantly higher prevalence of fecal coliforms $(58 \%)$ in stored water for washing than the stored water for drinking (28\%) and tap/tube well water (8\%) collected (Palit et al., 2012). Samples containing stored water for washing also had the highest non-permissible range of physico-chemical parameters. Household water containers storing water for washing were rich in fecal coliforms and residual chlorine contents. Palit et al. (2012) found less than the satisfactory level of residual chlorine (57\%), TDS (37\%), and $\mathrm{pH}(20 \%)$ present in almost two thirds of the samples of water stored for washing (Palit et al., 2012).

\section{Urban Water Security}

The urban water security index (UWSI) reveals the intrinsic spatial disparity of water security within the city as a combined result of physical setup of the cityscape including subsurface structures, over-ground infrastructure as well as social inequality and exclusions (Sultana, 2020). The most water insecure boroughs are those which are either regarded colloquially (because, unlike many cities, Kolkata does not have any official central business district) as the "central business district" (borough VI) where the main railway station, Sealdah and the biggest market, Burrabazar, are located, and the area which is going through a continuous infrastructural alteration due to urbanization (borough XIII and XVI) including bridges and other developmental activities are taking place (KMC report, 2012a, 2018; Roy and Dhali, 2016; Times of India, 2019). The subsurface structure of the city having active clay layer, age of the existing sewage system, non-biodegradable solid waste generation, lack of adequate pumping stations to remove water from the water logged areas, land subsidence, sporadic development of high-rise buildings, increasing traffic on the roads (particularly in the central city areas) and increasing density of population in these areas are to be blamed for the water insecurity (Roy and Dhali, 2016; KMC report, 2018; Mukherjee et al., 2018). Borough XVI has another issue with water and its infrastructure as this borough includes the newly added areas which still lack required infrastructure like direct piped water services to the households (KMC report, 2012a; Mukherjee et al., 2018, 2020).

Multiple intersecting dimensions must be analyzed and considered to fully understand water security. Here we have shown intersecting points between water insecurity and societal disadvantages related to gender, deprivation, social class, caste, ethnicity, and religion (Simpson, 2009; Thompson, 2016). These intersectional disparities are particularly critical for cis-women, other gendered people and for making progress toward both SDG 5 (gender equality and empower all women and girls). To achieve
SDG 6 (clean water and sanitation for all) we need to ensure we take into account these groups of people so we can ensure inclusive water security for everyone in a city (Truelove, 2011; Sultana, 2020; Dickin et al., 2021, p. 1). The participation of cis-female in the labor force is still considerably low across developing countries and emerging economics comparison to cis-male (Bhagat et al., 2008; Kundu and Mohanan, 2009; Agbodji et al., 2015; Biswas, 2018). Despite of the fact that the (cis)male-female gender gap has slowly decreased, cis-female workers have much lower participation rates than their cismale counterparts and hence comprise a marginalized section (ILO, 2016; Biswas, 2018; Deshpande, 2020). As per census2011 of India, the workforce participation rate for cis-females is $25.51 \%$ against $53.26 \%$ for cis-males in India as a whole and $18.08 \%$ against the $57.07 \%$ in West Bengal (Govt-WB, 2015; Biswas, 2018; Deshpande, 2020). Our survey results show that $31 \%$ cis-male respondents and $27.6 \%$ cis-female are employed. This is important in our analysis as we can better understand the particular water security issues related to where different groups experience what water security issues, i.e., cis-men in Kolkata are more vulnerable to water insecurity at their workplaces. In Kolkata (and India in general), the $\mathrm{WaSH}$ facilities both at workplaces and institutions, for all gendered, are either inadequate or are in poor condition (UN report, 2019; Paul et al., 2020). This type of focus can also bring us to look at conditions in schools, where (in India), 50\% children do not have access to a toilet at school, within them $22 \%$ are cis-men (Deivam, 2016; Tiberghien, 2016). This scenario is same in other public places, including the marketplaces and railways stations where thousands of people commute through every day (Paul et al., 2020).

Water security issues experienced by trans, and other gendered people are even worse. They are not properly registered officially-often live-in high levels of deprivation and poverty and are not able to access work (Dhall and Boyce, 2015; Boyce et al., 2018). This means they on the one hand share characteristics and WaSH struggles of those living in poverty but have the double burden of the hostility toward their very way of living and identity (Dhall and Boyce, 2015; Boyce et al., 2018). Thus, they often face physical humiliation during fetching water or using the common public latrines (Boyce et al., 2018; Mukherjee et al., 2020). Therefore, the results from our survey showing the number of transgender inclusive public toilets (14; Figure 2C) are crucial, as they are among the first attempts at demonstrating the exclusion factor for achieving water security in Kolkata city.

The result of UWSI also depicts that the portion of the respondents who are regarded as working in "household" are the most water-secure and most of them are cis- women. However, as we have shown, this does not mean that cis- women overall are more water secure than men. What this does point to is a need to understand the complex set of factors differentiating and influencing people's water security when it comes to looking at water security by gender. The next section of this paragraph will speak about cis-women and as there is no national level statistics on trans-women's data as of now. Chances are high that a major portion of cis-women having higher education are not engaged in active workforce. This non-engagement of 
cis- women in active workforce does not only reduces their role as decision-maker about $\mathrm{WaSH}$ expenditures at home, but also for their workplaces lessening cis-women's empowerment and gender equality at work (Dickin et al., 2021, p. 1). This assumption is supported by a study which states that the Gross Enrolment Ratio in higher education for male population is $18.3 \%$ and for women it is $19.1 \%$ s for the year $2018-2019$ (Mitra and Ghara, 2019). In contrast, Chatterjee et al. (2018) showed that the Indian cis-women's work force participation is low. Recent studies have observed that cis-women's education has largely $J$-shaped or $U$-shaped relationship with their workforce participation, particularly in India (Reddy, 1979; Sathar and Desai, 2000; Kingdon and Unni, 2001; Das and Desai, 2003; Das, 2006; Klasen and Pieters, 2015). Past studies asserted that both cultural factors (for example, norms restricting the mobility of women) and structural factors (for example, lack of appropriate job opportunities for educated women) play important roles in determining the $U$-shaped relationship between cis-women's education and work-force participation in India (Das and Desai, 2003; Chatterjee et al., 2018).

The 2011 census reports that $87.3 \%$ of office clerks and $93.1 \%$ of sales jobs are taken by cis-men (Chatterjee et al., 2018). Rather than demonstrating the lack of adequate jobs for moderately educated groups in the country, these statistics especially imply the exclusion of women from these jobs which explains the low rates of work-force participation for these women. Nevertheless, skilled work in education sector (and health sector) is not entirely gender segregated except in part, where some types of work, such as nursing, fit better with gender stereotypes of women's nurturing roles (Chatterjee et al., 2018). Then, much of these works necessitate education beyond secondary level. Therefore, the "weaker sex" segregation in these jobs ends in a greater demand for educated female workforce and the rise in workforce participation can then be observed among female having Bachelors' degree and above. According to the Census 2011, in India, more than three-quarters of teachers have education above secondary level, and over one-third of them, $36.8 \%$, are women (Chatterjee et al., 2018). Therefore, WaSH provisions in educational institution (Paul et al., 2020) would also matter for the low water security of the respondents with Postgraduate degrees and above, considering the similar situation for the cis-male teachers.

Lack of and inadequacy of $\mathrm{WaSH}$ provision in the socially deprived areas in Kolkata is also influencing some boroughs' overall UWSI scores (Mukherjee et al., 2020), such as borough XIII. Moreover, the statistically significant correlations between water accessibility variable and monthly income, caste, religion, education, and employment status of the respondent show that water insecurity and social exclusion go hand in hand. We can see this in the socially deprived areas of borough XIII, where the majority are of Muslim religion having lower level of education and monthly household income, and we have a low UWS score. Within the city's deprived areas, $81 \%$ of the dwellers have direct piped water supply in their houses for drinking purpose; among them only $8 \%$ use the same supplied water for other household works such as toilet flushing, washing clothes etc (Mukherjee et al., 2020). However, $43 \%$ of the dwellers from these deprived areas depend on water from standposts outside their houses for household tasks other than drinking (Mukherjee et al., 2020). Gender inequalities play an important role here. Cultural aspects related to religion is found to shape water insecurity for different genders due to the influence they have on division of household tasks as well as on and restriction of certain social interactions. This links to Schenk's (2010) work, where they found that Muslim women are more water insecure in the deprived areas as they are not allowed to go outside to take bath) which made it difficult to maintain hygiene particularly in the summer days. This significant public exposure may not be a problem for Hindu women from the lower income groups living in those deprived areas in the city, which make them choose occupations like domestic servants or vegetable vendors (Roy et al., 1992; Schenk, 2010). These cultural factors are also behind the under-representation of Muslims women in higher education and employment which shape their water security in Kolkata (Roy et al., 1992; Schenk, 2010; Rahaman and Barman, 2015; Mollah, 2018; Mukherjee et al., 2020).

\section{CONCLUSIONS}

The inclusive framework for urban water security assessment presented in this article highlights the challenges of urban water security (UWS) in Kolkata which goes beyond traditional indicators such as quantity of supplied water, access to water and sanitation or water quality. It captures the issues of water (in)security holistically along the four major dimensions of UWS-availability, accessibility, quality water-related risk and hazards. It does so by drawing on bio-physical and social indicators to answer the key questions of UWS: how, for whom and where a city is water insecure. To answer this the empirical approach of the study used spatial analysis of all the components of UWS with a megacity perspective from a location within an emerging economy. The findings suggest that water insecurity of a city is not only due to the malfunction or inadequacy of city's water system but also stems from the intersecting disadvantages, inequalities, and exclusion found in a society. Along with conventional quantifiable components of bio-physico-chemical dimensions, social factors were included as a key dimension of UWS to capture and improve our understanding of UWS, and as a result provide better recommendations for effective policy measures.

Despite being water blessed by having River Hugli in the west, East Kolkata Wetlands in the east and vast groundwater reserve, Kolkata faces a range of UWS challenges. Declining inland surface waterbodies and their littoral zones due to the changes in urban land use, increasing water demand owing to population growth, poor sanitation and lack of enough water treatment facilities coupled with mismanagement, issues associated with unplanned, excessive, and 'unaccountable' groundwater extractions such as depletion of groundwater level, land subsidence and aquifer contamination aggravated the water insecurities in Kolkata. In emerging and developing countries like India, these challenges affect urban dwellers, who experience difficulties in meeting daily water needs. The gap between the 
availability, supply and demand for fresh water will widen even further in mega cities in emerging countries, where this unequal state of urban water security affects mostly the people residing in the societal margins. This means we need to direct our attention to the consequences for public health, livelihoods, and wellbeing of these populations, with a particular focus on gender disparities. Municipal governments, as a result, need to constantly reconcile available water supply with growing demand in an equitable manner.

The existing literature on UWS assessments is not holistic or inclusive and rarely considers both bio-physical and societal factors in consider quantitatively. Therefore, we cannot apply any already established weighting methods to all the indicators of UWS. Lack of representation of the ground reality and underestimating the micro level issues may produce a fragmented scene of the UWS. The limited number of respondents to the survey questionnaires, their individual background, beliefs, ideology, and personal judgment about water security produce uncertainty and subjectivity in the indicator scores. We do, however, have a large enough random sample to provide strong and robust findings. Moreover, scoring through qualitative interpretations of the existing literature could weaken the precision of the findings. To overcome this issue, we weighed the data according to the Census-2011 to accurately reflect the population studied (particularly for gender and religion categories). However, the data were aggregated spatially into borough level, which lost the heterogeneity at the ward level scale. This way, we may have lost valuable information about the inequality present in the water security spectrum across the city.

Overall, this study provides a unique quantitative indexbased assessment framework to quantify UWS at the borough level and to define the presence of multiple intersecting dimensions between bio-physical environment and society. This study identifies water-insecure areas within an Indian megacity which are under deprivation in both spatially and socially beyond the possibilities of limited resources prudently. This novel quantitative approach would help policy makers and water stakeholders to fix their objectives to manage their available water and social resources judiciously toward achieving UWS managing the trade-offs and equity challenges. The variation within the city builds on and adds to our argument in the previous studies and underlines the need to look at within city variation in our future work where we would focus on more individual level from the data collection, validation approaches to index creation to prevail over this critical issue of urban water security.

\section{REFERENCES}

Aboelnga, H. T., El-Naser, H., Ribbe, L., and Frechen, F. B. (2020). Assessing water security in water-scarce cities: applying the integrated urban water security index (IUWSI) in Madaba, Jordan. Water 12:1299. doi: 10.3390/w120 51299

Aboelnga, H. T., Ribbe, L., Frechen, F. B., and Saghir, J. (2019). Urban Water security: definition and assessment framework. Resources 8:178. doi: $10.3390 /$ resources 8040178

\section{DATA AVAILABILITY STATEMENT}

The original contributions presented in the study are included in the article/Supplementary Material, further inquiries can be directed to the corresponding author/s.

\section{AUTHOR CONTRIBUTIONS}

SM: conceptualization, methodology, validation, formal analysis, investigation, data curation, visualization, and writing-original draft preparation. SM and TS: software and resources. TS, PS, and BS: writing-review and editing. BS: supervision. SM and BS: project administration and funding acquisition. All authors contributed to the article and approved the submitted version.

\section{FUNDING}

We thank the German Academic Exchange Service (DAAD Research Grants - Doctoral Programmes in Germany funding no. 57299294) who provides a fellowship to conduct this study. We would like to thank the GeoX Network for additional supports for conducting surveys and organizing interviews. We also acknowledge financial support by the German Research Foundation and the Open Access Publication Fund of the Freie Universität Berlin. The publication of this article was funded by Freie Universität Berlin.

\section{ACKNOWLEDGMENTS}

We would like to express our sincere gratitude to Prof. (Dr.) Kai Hartmann, Department of Earth Sciences, Freie Universität Berlin, Prof. (Dr.) Mahalaya Chatterjee, University of Calcutta, India and Dr. Dipankar Bhattacharya, KMDA, India who provided relevant data, insight, and expertise that greatly assisted the research. We are indebted to Dr. Dipanwita Chatterjee for her continuous assistance in Mapping. We would also like to show our gratitude to Mr. Sougata Saha, Comtel Consultants and Infraproject Pvt Ltd., India and Mr. Surajit Kar, Doctoral Researcher, University of Calcutta, India for assistance with Survey and Mapping during this research, and we thank the three reviewers for their insights.

\section{SUPPLEMENTARY MATERIAL}

The Supplementary Material for this article can be found online at: https://www.frontiersin.org/articles/10.3389/frwa. 2022.834239/full\#supplementary-material

Adams, E. A. (2017). Thirsty slums in African cities: household water insecurity in urban informal settlements of Lilongwe, Malawi. Int. J. Water Resourc. Dev. 34:869-887. doi: 10.1080/07900627.2017.1322941

ADB (2011). Kolkata Environment Improvement Investment Program Feasibility Assessment. Manila: Asian Development Bank.

Agbodji, A. E., Batana, Y. M., and Ouedraogo, D. (2015). Gender inequality in multidimensional welfare deprivation in West Africa: the case of Burkina Faso and Togo. Int. J. Soc. Econ.42, 980-1004. doi: 10.1108/IJSE-11-20 13-0270 
Aihara, Y., Shrestha, S., Kazama, F., and Nishida, K. (2015). Validation of household water insecurity scale in urban Nepal. Water Policy 17, 1019-1032. doi: 10.2166/wp.2015.116

Ali, M., Khan, S. J., Aslam, I., and Khan, Z. (2018). Simulation of the impacts of land-use change on surface runoff of Lai Nullah Basin in Islamabad, Pakistan. Landscape Urban Plan. 102, 271-279. doi: 10.1016/j.landurbplan.2011. 05.006

Allan, J. V., Kenway, S. J., and Head, B. W. (2018). Urban water security-what does it mean? Urban Water J. 15, 899-910. doi: 10.1080/1573062X.2019.1574843

Alston, M., and Whittenbury, K. (2013). Does climatic crisis in Australia's food bowl create a basis for change in agricultural gender relations? Agric. Hum. Values 30(1), 115-128. doi: 10.1007/s10460-012-9382-x

Anne, M., Callahan, J. L., and Kang, H. (2013). Gender and caste intersectionality in the Indian context. Hum. Resourc. Manag. 2013, 31-48. Available online at: https://www.infona.pl/resource/bwmetal.element.desklight-be64aaaa-4cf7441d-91ab-160bdd31ad1a (accessed January 29, 2022).

Basu, J. (2016). Kolkata, a Water-Rich City Turning Water-Poor. The Third Pole. Available online at: https:/www.thethirdpole.net/2015/11/11/kolkata-a-waterrich-city-turning-water-poor (accessed February 24, 2021).

Bhagat, R. B., Das, K. C., Sebastian, D., and Mohanty, S. (2008). Levels, trends and structure of workforce in India: census based study 1981-2001. Int. Inst. Popul. Sci. 1-182. Available online at: https://scholar.google.co.in/citations?view_op= view_citation\&hl=en\&user $=$ a436P_QAAAAJ\&cstart $=100 \&$ pagesize $=100 \&$ sortby=title\&citation_for_view=a436P_QAAAAJ:mVmsd5A6BfQC (accessed January 29, 2022).

Biswas, S. (2018). Work participation rate of women in West Bengal. Int. J. Res. Hum. Arts Liter. 6, 423-434.

Boyce, P., Brown, S., Cavill, S., Chaukekar, S., Chisenga, B., Dash, M., et al. (2018). Transgender-inclusive sanitation: insights from South Asia. Waterlines 37, 102-117. doi: 10.3362/1756-3488.18-00004

Castán Broto, V., and Neves Alves, S. (2018). Intersectionality challenges for the co-production of urban services: notes for a theoretical and methodological agenda. Environ. Urban. 30, 367-386. doi: 10.1177/0956247818790208

Census of India (2011). Rural-Urban Distribution of Population (Provisional Population Totals). The Registrar General and Census Commissioner, India, New Delhi. Census of India. Available online at: http://censusindia.gov.in/2011prov-results/PPT_2.html (accessed April 4, 2020).

Chakravarty, I. (2007). Water Problems for Kolkata Metropolitan Region, Ballardie Thompson and Matthews Pvt. Ltd. Available online at: www.sulabhenvis.in/ admin/.../Kolkata\%20Sewerage\%20systems.pdf (accessed February 02, 2020).

Chatterjee, A. (2014). Water Supply System in Kolkata City and Adjoining Areas. Available online at: https://medium.com/@anjan.chatterjee/watersupply-system-in-kolkata-city-and-adjoining-areas-b199099a4517 (accessed November 12, 2020).

Chatterjee, B., and Roy, A. (2021). Creating Urban Water Resilience in India: A Water Balance Study of Chennai, Bengaluru, Coimbatore, and Delhi. Observer Research Foundation, India. Available online at: https://www.orfonline. org/wp-content/uploads/2021/03/Monograph_Urban_Water.pdf (accessed August 6, 2021).

Chatterjee, E., Desai, S., and Vanneman, R. (2018). Indian paradox: rising education, declining women's employment. Demogr. Res. 38:855. doi: 10.4054/DemRes.2018.38.31

Chen, L., Zhang, G., Xu, Y. J., Chen, S., Wu, Y., Gao, Z., et al. (2020). Human activities and climate variability affecting inland water surface area in a high latitude river basin. Water 12:382. doi: 10.3390/w12020382

Clement, F. (2013). "From water productivity to water security: a paradigm shift," in Water Security Principles, Perspectives and Practices, ed B.A. Lankford (Abingdon, VA: Routledge), 148-165.

Cook, C., and Bakker, K. (2012). Water security: debating an emerging paradigm. Glob. Environ. Change 22, 94-102. doi: 10.1016/j.gloenvcha.2011. 10.011

Das, M. B. (2006). Do Traditional Axes of Exclusion Affect Labor Market Outcomes in India? South Asia Series, Paper No. 97. Washington, DC: World Bank.

Das, M. B., and Desai, S. (2003). Are Educated Women Less Likely to be Employed in India? Social Protection Discussion Paper No. 313. Washington, DC: World Bank.

Day, D. (1996). Water as a social good. Austral. J. Environ. Manage. 3, 26-41. doi: $10.1080 / 14486563.1996 .10648341$
Deivam, M. (2016). Wash environment at school: a vision of clean India. Int. J. Hum. Soc. Sci. Res. 2, 40-44.

Demetriades, J., and Esplen, E. (2010). "The gender dimensions of poverty and climate change adaptation," in Social Dimensions of Climate Change: Equity and Vulnerability in a Warming World, eds R. Mearns, A. Norton (Washington, DC: The World Bank), 133-144.

Denton, F. (2002). Climate change vulnerability, impacts, and adaptation: why does gender matter? Gend. Dev. 10, 10-20. doi: 10.1080/13552070215903

Deshpande, A. (2020). Early effects of lockdown in India: gender gaps in job losses and domestic work. Indian J. Lab. Econ. 63, 87-90. doi: 10.1007/s41027-020-00261-2

Dhall, P., and Boyce, P. (2015). Livelihood, Exclusion, and Opportunity: Socioeconomic Welfare Among Gender and Sexuality Non-Normative People in India. Brighton: Institute of Development Studies.

Dickin, S., Bisung, E., Nansi, J., and Charles, K. (2021). Empowerment in water, sanitation and hygiene index. World Dev. 137:105158. doi: 10.1016/j.worlddev.2020.105158

Douglas, I. (1983). The Urban Environment. London: Edward Arnold (Publisher). Ltd.,

Feng, X., Zhang, G., and Yin, X. (2010). Hydrological responses to climate change in Nenjiang river basin, Northeastern China. Water Resour. Manag. 25, 677-689. doi: 10.1007/s11269-0109720-y

Filmer, D., and Pritchett, L. H. (2001). Estimating wealth effects without expenditure data -or tears: an application to educational enrolments in states of India. Demography 38, 115-132. doi: 10.1353/dem.2001.0003

Fletcher, A. J. (2018). "More than women and men: a framework for gender and intersectionality research on environmental crisis and conflict," in Water Security Across the Gender Divide, eds C. Fröhlich, G. Gioli, R. Cremades, and H. Myrttinen (Cham: Springer), 35-58. doi: 10.1007/978-3-319-64046-4_3

Forman, R. (ed.). (2014). "Urban water bodies," in Urban Ecology: Science of Cities (Cambridge: Cambridge University Press), 175-204. doi: 10.1017/CBO9781139030472.009

Garrick, D., and Hall, W. J. (2014). Water security and society: risks, metrics, and pathways. Annu. Rev. Environ. Resour. 39, 611-639. doi: 10.1146/annurev-environ-013012-093817

Ghosh, G. K. (2002). Water of India: (Quality and Quantity). New Delhi: APH Publishing Corporation.

Giddings, B., Hopwood, B., and O’brien, G. (2002). Environment, economy and society: fitting them together into sustainable development. Sust. Dev. 10, 187-196. doi: 10.1002/sd.199

Giordano, M. (2017). "Water security," in The International Encyclopedia of Geography: People, the Earth, Environment, and Technology, Vol. 1, ed D. Richardson (Hoboken, NJ: JohnWiley and Sons). doi: 10.1002/9781118786352.wbieg0536

Gleick, P. H. (2004). The World's Water 2004-2005: The Biennial Report on Freshwater Resources. Washington, DC: Island Press.

Global Water Partnership (2019). GWP Strategy 2020-2025: Mobilising for a Water Secure World. Stockholm: GWP. Available online at: https://www.gwp.org/ globalassets/global/about-gwp/strategic-documents/gwp-strategy-2020-2025. pdf\%20accessed\%20January\%2016,\%202021 (accessed January 16, 2021).

Gopalakrishnan, S. (2016). No Public Toilets for Transgenders in the Country. India Water Portal. Available online at: http://sanitation.indiawaterportal.org/ english/node/4832 (accessed April 16, 2020).

Govt-WB (2015). State Statistical Handbook West Bengal 2014. Kolkata: Bureau of Applied Economics and Statistics, Department of Statistics and Programme Implementation, Government of West Bengal.

Grey, D., and Sadoff, C. W. (2007). Sink or Swim? Water security for growth and development. Water Policy 9, 545-571. doi: 10.2166/wp.2007.021

Hagler, B. (2007). Environmental Baseline Study of Margala and Margala North Blocks. Islamabad: MOL Pakistan Oil and Gas Company BV.

Harris, L., Kleiber, D., Goldin, J., Darkwah, A., and Morinville, C. (2017). Intersections of gender and water: comparative approaches to everyday gendered negotiations of water access in underserved areas of Accra, Ghana and Cape Town, South Africa. J. Gend. Stud. 26, 561-582. doi: 10.1080/09589236.2016.1150819

Hati, P., Roy, G., Bhattacharyya, I., Kundu, D., and Sengupta, D. (2020). Present scenario of water supply in Kolkata. Int. Res. J. Eng. Technol. 7, 4060-4066. 
Hellberg, S. (2017). Water for survival, water for pleasure-A biopolitical perspective on the social sustainability of the basic water agenda. Water Alternat. 10:65. Available online at: http://www.water-alternatives.org/index. php/alldoc/articles/vol10/v10issue1/342-a10-1-4/file (accessed January 29, 2022).

Hoekstra, A. Y. (2000). Appreciation of water: Four perspectives. Water Pol. 1, 605-622. Available online at: https://ayhoekstra.nl/pubs/Hoekstra-1998.pdf

ILO (2016). Women at Work: Trends 2016. Geneva: International Labour Office. Available online at: http://www.ilo.org/wcmsp5/groups/public/--dgreports/---dcomm/---publ/documents/publication/wcms_457317.pdf? utm_content=buffer92781\&utm_medium $=$ social\&utm_source=twitter.com\& utm_campaign=buffer (Accessed February 22, 2021).

Kingdon, G. G., and Unni, J. (2001). Education and women's labour market outcomes in India. Educ. Econ. 9, 173-195. doi: 10.1080/0964529011005 6994

Kiran, R., and Ramachandra, T. V. (1999). Status of Wetlands in Bangalore and its Conservation aspects. ENVIS J. Hum. Settle. 16-24.

Klasen, S., and Pieters, J. (2015). What explains the stagnation of female labor force participation in urban India? World Bank Econ. Rev. 29, 449-478. doi: 10.1093/wber/lhv003

KMC report (2012a). Kolkata Urban Sector Investment Plan. Kolkata: Kolkata Municipal Corporation.

KMC report (2012b). Kolkata Environmental Improvement Investment Program (Tranche 1)-Sewerage and Drainage Subproject. Kolkata Municipal Corporation. Kolkata. Available online at: http://www.keiip.in/bl3/pdf/ 42266-023-ind-iee-02.pdf (accessed February 22, 2021).

KMC report (2018). City Disaster Management Plan of Kolkata. Available online at: http://wbdmd.gov.in/writereaddata/uploaded/DP/DPKolkata33359. pdf (accessed February 22, 2021).

Kundu, A., and Mohanan, P. C. (2009). "Employment and inequality outcomes in India," in Joint Seminar on Employment and Inequality, organized by the Employment, Labour and Social Affairs Directorate and Development Centre (Paris), 1-43.

Kundu, N. (2003). The Case of Kolkata, India. Understanding Slums: Case Studies for the Global Report on Human Settlements. London: UN-Habitat; Earthscan, 195-228 (Available online at: http://www.ucl.ac.uk/dpu-projects/ Global_Report/cities/kolkata.htm (accessed October 20, 2016).

Lundqvist, J., Appasamy, P., and Nelliyat, P. (2003). Dimensions and approaches for Third World city water security. Philos. Trans. R. Soc. Lond. Ser. B Biol. Sci. 358, 1985-1996. doi: 10.1098/rstb.2003.1382

MacGregor, S. (2009). A stranger silence still: the need for feminist social research on climate change. Sociol. Rev. 57, 124-140. doi: 10.1111/j.1467-954X.2010.01889.x

Maiti, S., and Agrawal, P. K. (2005). Environmental degradation in the context of growing urbanization: a focus on the metropolitan cities of India. J. Hum. Ecol. 17, 277-287. doi: 10.1080/09709274.2005.11 905793

Mandal, J., Ghosh, N., and Mukhopadhyay, A. (2019). Urban growth dynamics and changing land-use land-cover of megacity Kolkata and its environs. J. Indian Soc. Remote Sens. 47, 1707-1725. doi: 10.1007/s12524-019-0 $1020-7$

Manteghi, G., bin Limit, H., and Remaz, D. (2015). Water bodies an urban microclimate: a review. Mod. Appl. Sci. 9:1. doi: 10.5539/mas.v9n6p1

May, V. M. (2015). Persuing Intersectionality, Unsettling Dominant Imaginaries. New York, NY: Routledge. doi: 10.4324/9780203141991

McArthur, J. M., Sikdar, P. K., Leng, M. J., Ghosal, U., and Sen,. I. (2018). Groundwater quality beneath an Asian megacity on a delta: Kolkata's (Calcutta's) disappearing arsenic and present manganese. Environ. Sci. Technol. 52, 5161-5172. doi: 10.1021/acs.est.7b04996

Mendoza, M. E., Granados, E. L., Geneletti, D., Perez-Salicrup, D. R., and Salinas, V. (2011). Analysing land cover and land use change processes at watershed level: a multi temporal study in the Lake Cuitzeo Watershed, Mexico (1975-2003). Appl. Geogr. 31, 237-250. doi: 10.1016/j.apgeog.2010. 05.010

Mitra, D., and Ghara, T. K. (2019). Gross enrolment ratio in higher education: a district level analysis of the state of West Bengal. Asian Rev. Soc. Sci. 8, 37-41. doi: 10.51983/arss-2019.8.3.1600
Mohan, M., Pathan, S., Narendrareddy, K., Kandya, A., and Pandey, S. (2011). Dynamics of urbanization and its impact on land-use/land-cover: a case study of megacity Delhi. J. Environ. Prot. 2, 1274-1283. doi: 10.4236/jep.2011.29147

Mollah, K. (2018). Status of Muslim Women in West Bengal. Available online at: http://ijrar.com/upload_issue/ijrar_issue_936.pdf (accessed February 22, 2021).

Moss, D. (2008). EUNIS Habitat Classification-A Guide for Users. European Topic Centre on Biological Diversity. Available online at: http://citeseerx.ist.psu. edu/viewdoc/download?doi=10.1.1.231.4607\&rep=rep1\&type=pdf $\quad$ (accessed November 9, 2021).

Mukherjee, J., and Ghosh, A. (2015). "Water justice city profile: Kolkata, India," in Translocal learning for water justice: Peri-urban pathways in India, Tanzania and Bolivia (London: The Bartlett Development Planning Unit). Available online at: https://www.ucl.ac.uk/bartlett/development/sites/bartlett/ files/kolkata_report.pdf (accessed March 5, 2021).

Mukherjee, S., Bebermeier, W., and Schütt, B. (2018). An overview of the impacts of land use land cover changes (1980-2014) on urban water security of Kolkata. Land 7:91. doi: 10.3390/land7030091

Mukherjee, S., Sundberg, T., and Schütt, B. (2020). Assessment of water security in socially excluded areas in Kolkata, India: an approach focusing on water, sanitation and hygiene. Water 12:746. doi: 10.3390/w12030746

Mukherjee, S., Sundberg, T., and Schütt, B. (2021). "Issues, dimensions and approaches of assessing urban water security in developing and emerging countries: an inclusive perspective," in Environmental Management: Issues and Concerns in Developing Countries, ed P. Sikdar (Springer), 151-184. doi: 10.1007/978-3-030-62529-0_9

Muller, M. (2016). Urban water security in Africa: the face of climate and development challenges. Dev. South. Africa 33, 67-80. doi: 10.1080/0376835X.2015.1113121

Neelakantan, T. R., and Ramakrishnan, K. (2017). Protection of urban water body infrastructure-policy requirements. EandES 80:012068. doi: 10.1088/1755-1315/80/1/012068

Nganyanyuka, K., Martinez, J., Wesselink, A., Lungo, J. H., and Georgiadou, Y. (2014). Accessing water services in Dar es Salaam: are we counting what counts? Hab. Int. 44, 358-366. doi: 10.1016/j.habitatint.2014.07.003

Obani, P., and Gupta, J. (2016). "Human security and access to water, sanitation, and hygiene: exploring the drivers and nexus," in Handbook on Water Security, eds C. Pahl-Wostl, A. Bhaduri, J. Gupta (Cheltenham and Northampton: Edward Elgar Publishing), 201-214.

OECD. (2016). Water Governance in Cities, OECD Studies on Water. Paris: OECD Publishing. doi: 10.1787/9789264251090-en

Palit, A., Batabyal, P., Kanungo, S., and Sur, D. (2012). In-house contamination of potable water in urban slum of Kolkata, India: a possible transmission route of diarrhea. Water Sci. Technol. 66 299-303. doi: 10.2166/wst.2012.177

Pangare, V. (2016). Gender Equality, Water and Climate Change Adaptation in Megacities. Water, Megacities and Global Change: Portraits of 15 Emblematic Cities of the World. Paris: UNESCO. Available online at: http://unesdoc.unesco. org/images/0024/002454/245419e.pdf (accessed March 7, 2018).

Paul, S. K., Kumar, R., Pal, R., and Ghosh, A. (2020). Safe drinking water and toilet facility in public places in India: what we need to do! J. Fam. Med. Prim. Care 9:2593. doi: $10.4103 /$ ffmpc.jfmpc_318_20

Rahaman, H., and Barman, H. (2015). Muslims and education of West Bengal: theory to pragmatism. Int. J. Hum. Soc. Sci. Invent. 4, 32-38.

Raschka, S. (2015). Principal Component Analysis in 3 Simple Steps. Available online at: https://sebastianraschka.com/Articles/2015_pca_in_3_steps.html (accessed March 2, 2021).

Ray, I. (2007). Women, water, and development. Ann. Rev. Environ. Resourc. 32, 421-449. doi: 10.1146/annurev.energy.32.041806.143704

Reddy, D. N. (1979). Female work participation in India: facts, problems, and policies. Ind. J. Indust. Relat. 15, 197-212.

Rogers, P., Bhatia, R., and Huber, A. (1998). Water as a Social and Economic Good: How to Put the Principle Into Practice. Stockholm: Global Water Partnership. Available online at: http://dlc.dlib.indiana.edu/dlc/bitstream/handle/10535/ 4989/TAC2.PDF?sequence=1_1 (accessed November 9, 2021).

Romero-Lankao, P., and Gnatz, D. M. (2016). Conceptualizing urban water security in an urbanizing world. Curr. Opin. Environ. Sust. 21, 45-51. doi: $10.1016 /$ j.cosust.2016.11.002 
Rouse, M. J. (2013). Institutional Governance and Regulation of Water Services. London: IWA Publishing. doi: 10.2166/9781780404516

Roy, P., Ghosh, A., and Sinha, R. (1992). Measuring bustee environment in Calcutta. Soc. Change 22, 128-130.

Roy, R., and Dhali, M. (2016). Seasonal water logging problem in a mega city: a study of Kolkata, India. J. Res. 430, 1-9.

Sahu, P., Michael, H. A., Voss, C. I., and Sikdar, P. K. (2013). Impacts on groundwater recharge areas of megacity pumping: analysis of potential contamination of Kolkata, India, water supply. Hydrol. Sci. J. 58, 1340-1360. doi: 10.1080/02626667.2013.813946

Saravanan, S. (2010). Violence Against Women in India: A Literature Review. Available online at: http://182.71.188.10:8080/jspui/bitstream/123456789/98/1/ Violence\%20Against\%20Women\%20India\%20-\%2025.pdf (accessed April 14, 2020).

Satapathy, B. K. (2014). Safe drinking water in slums. Econ. Polit. Wkly. 49, 51.

Sathar, Z., and Desai, S. (2000). "Class and gender in rural Pakistan: Differentials in economic activity," in Women, Poverty and Demographic Change, ed B. Garcia (Oxford: Oxford University Press), 175-192.

Satterthwaite, D. (2016). Missing the millennium development goal targets for water and sanitation in urban areas. Environ. Urban. 28, 99-118. doi: $10.1177 / 0956247816628435$

Sau, A. (2017). A study on water supply and sanitation at a slum in Kolkata. Int. J. Med. Sci. Public Health 6, 634-637. doi: 10.5455/ijmsph.2017.0739414112016

Schenk, C. (2010). Slum diversity in Kolkata. Columbia Undergrad. J. South Asian Stud 1, 91-108. Available online: http://www.columbia.edu/cu/cujsas/Volume \%20I/Issue\%20II/W\%20Collin\%20Schenk\%20-\%20Slum\%20Diversity.pdf (accessed January 29, 2022

Shaban, A., Kourtit, K., and Nijkamp, P. (2020). India's urban system: sustainability and imbalanced growth of cities. Sustainability 12:2941. doi: 10.3390/su12072941

Shaban, A., and Sattar, S. (2011). Water security and sustainability in urban India. Int. J. Glob. Environ. Issues 11, 231-254. doi: 10.1504/IJGENVI.2011.044552

Shahid, S., and Pelling, M. (2020). Leaving no One Behind in Tomorrow's Cities: Strengthening Gender, Intersectionality and Social Inclusion in the COVID-19 Crisis and Beyond, Tomorrow's Cities Comment \#6, May 2020. Available online at: https://tomorrowscities.org/leaving-no-one-behind-tomorrowscities-strengthening-gender-intersectionality-and-social-inclusion (accessed November 9, 2021).

Shrestha, S., Aihara, Y., Bhattarai, A. P., Bista, N., Kondo, N., Futaba, K., et al. (2018). Development of an objective water security index and assessment of its association with quality of life in urban areas of developing countries. SSM Popul. Health 6, 276-285. doi: 10.1016/j.ssmph.2018.10.007

Simpson, J. (2009). Everyone Belongs: A Toolkit for Applying Intersectionality. Canadian Research Institute for the Advancement of Women (CRIAW), Ottawa, Canada. Available online at:http://also-chicago.org/also_site/ wp-content/uploads/2017/03/Everyone_Belongs-A-toolkit-for-applyingintersectionality.pdf (accessed January 30, 2022).

Singh, R., Maheshwari, B., and Malano, H. M. (2009). "Developing a conceptual model for water accounting in peri-urban catchments," in 18th World IMACS Congress and MODSIM09 International Congress on Modelling and Simulation. Modelling and Simulation Society of Australia and New Zealand and International Association for Mathematics and Computers in Simulation, eds R. S. Anderssen, R. D. Braddock, L. T. H. Newham (Cairns: 18th World IMACS / MODSIM Congress) 2377-2383.

Srinivasan, V., Konar, M., and Sivapalan, M. (2017). A dynamic framework for water security. Water Sec. 1, 12-20. doi: 10.1016/j.wasec.2017.03.001

Sullivan, C. A. (2011). Quantifying water vulnerability: a multidimensional approach. Stochast. Environ. Res. Risk Assess. 25, 627-640. doi: $10.1007 / \mathrm{s} 00477-010-0426-8$

Sultana, F. (2020). Embodied intersectionalities of urban citizenship:water, infrastructure, and gender in the global South. Ann. Am. Assoc. Geogr. 110, 1407-1424. doi: 10.1080/24694452.2020.1715193

Thompson, J. A. (2016). Intersectionality and water: how social relations intersect with ecological difference. Gend. Place Cult. 23, 1286-1301. doi: 10.1080/0966369X.2016.1160038

Tiberghien, J. (2016). WaterAid School WASH Research: India Country Report. Available online at: https://washmatters.wateraid.org/sites/g/files/jkxoof256/
files/WaterAid\%20school\%20WASH\%20research\%20report\%20India.pdf (accessed March 5, 2021).

Times of India (2019). Majerhat Bridge Work may Have Caused Behala-Kidderpore Flood. Available online at: http://timesofindia.indiatimes.com/articleshow/ 70777574.cms?utm_source=contentofinterest\&utm_medium=text\&utm_ campaign $=$ cppst $($ accessed February 22, 2021).

Truelove, Y. (2011). (Re-) Conceptualizing water inequality in Delhi, India through a feminist political ecology framework. Geoforum 42, 143-152. doi: 10.1016/j.geoforum.2011.01.004

UN (2010). The Human Right to Water and Sanitation. Resolution Adopted by the General Assembly on 28 July 2010: 64/292. Paris: United Nations. Available online at: https://undocs.org/A/RES/64/292 (accessed April 14, 2020).

UN report (2019). Water, Sanitation and Hygiene. Paris: United Nations. Available online at: https://www.unwater.org/water-facts/water-sanitationand-hygiene/ (accessed February 22, 2021).

UNs (2015). Transforming Our World: The 2030 Agenda for Sustainable Development. Paris: United Nations. Available online at: https:// sustainabledevelopment.un.org/content/documents/21252030\%20Agenda \%20for\%20Sustainable\%20Development\%20web.pdf (accessed November 9, 2021).

Valentine, G. (2007). Theorizing and researching intersectionality: a challenge for feminist geography. Prof. Geogr. 59, 10-21. doi: $10.1111 / j .1467-9272.2007 .00587 . x$

van Ginkel, K. C., Hoekstra, A. Y., Buurman, J., and Hogeboom, R. J. (2018). Urban water security dashboard: Systems approach to characterizing the water security of cities. J. Water Resourc. Plan. Manag. 144:04018075. doi: 10.1061/(ASCE)WR.1943-5452.0000997

Veldkamp, T., Wada, Y., Aerts, J., Doll, P., Gosling, S. N., Liu, J., et al. (2017). Water scarcity hotspots travel downstream due to human interventions in the 20th and 21st century. Nat. Commun. 8:15697. doi: 10.1038/ncomms15697

Vörösmarty, C. J., Green, P., Salisbury, J., and Lammers, R. B. (2000). Global water resources: vulnerability from climate change and population growth. Science 289, 284-288. doi: 10.1126/science.289.5477.284

Vorosmarty, C. J., McIntyre, P. B., Gessner, M. O., Dudgeon, D., and Prusevich, A. (2010). Global threats to human water security and river biodiversity. Nature 467, 555-561. doi: 10.1038/nature 09440

Vyas, S., and Kumaranayake, L. (2006). Constructing socio-economic status indices: how touse principal components analysis. Health Policy Plan 21, 459-468. doi: 10.1093/heapol/czl029

Wallace, T., and Coles, A. (2005). "Water, gender and development: an introduction," in Gender, Water and Development, eds A. Coles, and T. Wallace (New York, NY: Berg Publishers), 1-20. doi: 10.4324/9781003085461-1

Wheater, H. S. (2015). "Water security - science and management challenges. hydrological sciences and water security: past, present and future," in Proceedings of the 11th Kovacs Colloquium (Paris).

Wheater, H. S., and Gober, P. (2014). "Meeting the science challenges of water security in the Saskatchewan River Basin: a regional hydroclimate project from Western Canada," in Dooge Nash International Symposium, eds J. J. O'Sullivan, and M. Bruen (Dublin: University College Dublin), 431-446.

WHO (2015). Water, Sanitation and Hygiene in Health Care Facilities: Status in Low- and Middle-Income Countries and Way Forward. Geneva: World Health Organization. Available online at: https://apps.who.int/iris/bitstream/handle/ 10665/154588/9789241508476_eng.pdf (accessed November 25, 2020).

WHO (2018). Guidelines on Sanitation and Health. Geneva: World Health Organization. Available online at: https://apps.who.int/iris/bitstream/handle/ 10665/274939/9789241514705-eng.pdf?ua=1 (accessed November 25, 2020).

WHO (2020). Unsafe Drinking-Water, Sanitation and Waste Management. Geneva: World Health Organization. Available online at: https://www.who.int/ sustainable-development/cities/health-risks/water-sanitation/en/ (accessed April 15, 2020).

WWAP (2019). Leaving no One Behind: The United Nations World Water Development Report-2019. Paris: World Water Assessment Programme; United Nations.

Young, K. (2015). Human Dimensions of Urban Water Bodies and Associated Green Spaces. (Master of Science Dissertation), Texas Tech University, USA. Available online at: https://tu-ir.tdl.org/bitstream/handle/2346/63580/ YOUNG-THESIS-2015.pdf?sequence=1 (accessed November 19, 2020). 
Yuval-Davis, N. (2006). Intersectionality and feminist politics. Euro. J. Womens Stud. 13, 193-209. doi: 10.1177/1350506806065752

Conflict of Interest: The authors declare that the research was conducted in the absence of any commercial or financial relationships that could be construed as a potential conflict of interest.

Publisher's Note: All claims expressed in this article are solely those of the authors and do not necessarily represent those of their affiliated organizations, or those of the publisher, the editors and the reviewers. Any product that may be evaluated in this article, or claim that may be made by its manufacturer, is not guaranteed or endorsed by the publisher.

Copyright (c) 2022 Mukherjee, Sundberg, Sikdar and Schütt. This is an open-access article distributed under the terms of the Creative Commons Attribution License (CC $B Y)$. The use, distribution or reproduction in other forums is permitted, provided the original author(s) and the copyright owner(s) are credited and that the original publication in this journal is cited, in accordance with accepted academic practice. No use, distribution or reproduction is permitted which does not comply with these terms. 